\title{
Enhanced gas separation performance of 6FDA-DAM based mixed matrix membranes by incorporating MOF UiO-66 and its derivatives
}

\author{
Mohd Zamidi Ahmad ${ }^{\mathrm{a}, \mathrm{b}, \mathrm{c}}$, Marta Navarro ${ }^{\mathrm{b}}$, Miloslav Lhotka ${ }^{\mathrm{a}}$, Beatriz Zornoza ${ }^{\mathrm{b}}$, Carlos Téllez ${ }^{\mathrm{b}}$, \\ Wiebe M. de Vos $^{\mathrm{c}}$, Nieck E. Benes ${ }^{\mathrm{c}}$, Nora M. Konnertz ${ }^{\mathrm{d}}$, Tymen Visser ${ }^{\mathrm{d}}$, Rocio Semino ${ }^{\mathrm{e}, \mathrm{f}}$, \\ Guillaume Maurin ${ }^{\mathrm{e}}$, Vlastimil Fila ${ }^{\mathrm{a}}$, Joaquín Coronas ${ }^{\mathrm{b}, *}$ \\ ${ }^{a}$ Department of Inorganic Technology, University of Chemistry and Technology, Technicka 5, Dejvice - Praha 6, 16628 Prague, Czech Republic \\ b Chemical and Environmental Engineering Department and Instituto de Nanociencia de Aragón (INA), Universidad de Zaragoza, 50018 Zaragoza, Spain \\ ${ }^{\mathrm{c}}$ Membrane Science and Technology, Faculty of Science and Technology, MESA + Institute for Nanotechnology, University of Twente, P.O. Box 217, AE Enschede, The \\ Netherlands \\ ${ }^{\mathrm{d}}$ European Membrane Institute Twente (EMI), Faculty of Science and Technology, University of Twente, P.O. Box 217, AE Enschede, The Netherlands \\ e Institut Charles Gerhardt Montpellier UMR 5253 CNRS, Université de Montpellier, Place E. Bataillon, 34095 Montpellier Cedex 05, France \\ ${ }^{\mathrm{f}}$ Institute of Materials, École Polytechnique Fédérale de Lausanne, 1015 Lausanne, Switzerland
}

\section{A R T I C L E I N F O}

\section{Keywords:}

Gas separation

6FDA-DAM

Metal organic framework

Zr-based MOF

Mixed matrix membrane

\begin{abstract}
A B S T R A C T
Functionalization and post-synthetic modification (PSM) of metal-organic frameworks (MOFs) are two important routes to obtain MOFs with full potential in mixed matrix membrane (MMM) fabrication. We synthesized UiO-66 and two derivatives UiO-66- $\mathrm{NH}_{2}$ and UiO-66-NH-COCH 3 with less than $50 \mathrm{~nm}$ particle size. The $\mathrm{CO}_{2}$ uptakes at 10 bar in the two functionalized UiO-66s were improved by $44 \%$ and $58 \%$, respectively, with respect to the pristine solid. The MOF nanoparticles were incorporated into the highly permeable polymer 6FDA-DAM, making MMMs with 5-24 wt\% particle loadings. All fillers and membranes were characterized accordingly, and their gas separation performances were evaluated by feeding $\mathrm{CO}_{2} / \mathrm{CH}_{4}$ equimolar mixtures at 2 bar pressure difference at $35^{\circ} \mathrm{C} . \mathrm{CO}_{2}$ permeability $\left(\mathrm{P}_{\mathrm{CO} 2}\right)$ of pristine 6FDA-DAM $\left(\mathrm{P}_{\mathrm{CO} 2}=997 \pm 48\right.$ Barrer, $\left.\alpha_{\mathrm{CO} 2 / \mathrm{CH} 4}=29 \pm 3\right)$ increased by $92 \%$ with $20 \mathrm{wt} \%$ UiO-66 loading, while maintaining the $\mathrm{CO}_{2} / \mathrm{CH}_{4}$ selectivity. Improvements of $23 \%$ and $27 \%$ were observed for $\mathrm{P}_{\mathrm{CO} 2}$ with the same $20 \mathrm{wt} \%$ loading of UiO-66- $\mathrm{NH}_{2}$ and UiO-66-NH-COCH 3 , respectively. The $\alpha_{\mathrm{CO} 2 / \mathrm{CH} 4}$ was improved up to $16 \%$ using both functionalized UiO- 66 type MOFs. The best separation performance in this work was obtained with $14 \mathrm{wt} \%$ UiO-66 MMM $\left(\mathrm{P}_{\mathrm{CO} 2}=1912 \pm 115 \mathrm{Barrer}, \alpha_{\mathrm{CO} 2 / \mathrm{CH} 4}\right.$ $=31 \pm 1), 16 \mathrm{wt} \%$ UiO-66- $\mathrm{NH}_{2}$ MMM $\left(\mathrm{P}_{\mathrm{CO} 2}=1223 \pm 23\right.$ Barrer, $\left.\alpha_{\mathrm{CO} 2 / \mathrm{CH} 4}=30 \pm 1\right)$ and $16 \mathrm{wt} \% \mathrm{UiO}-66-$ $\mathrm{NH}-\mathrm{COCH}_{3} \mathrm{MMM}\left(\mathrm{P}_{\mathrm{CO} 2}=1263 \pm 42\right.$ Barrer, $\left.\alpha_{\mathrm{CO} 2 / \mathrm{CH} 4}=33 \pm 1\right)$ at 2 bar feed pressure difference. The measurement was also conducted with various binary compositions $\left(\mathrm{CO}_{2}=10-90 \%\right)$, both at low and high pressures up to $40 \mathrm{bar}$ at $35^{\circ} \mathrm{C}$, showing no pressure-related $\mathrm{CO}_{2}$-induced plasticization. The atomistic modelling for the MOF/polymer interface was consistent with a moderate MOF surface coverage by 6FDA-DAM which did not play a detrimental role in the membrane performance.
\end{abstract}

\section{Introduction}

Natural gas sweetening by the removal of the acidic components $\left(\mathrm{CO}_{2}\right.$ and $\left.\mathrm{H}_{2} \mathrm{~S}\right)$ has been discussed thoroughly over the years [1], including advantages and disadvantages of the established and competing technologies $[2,3]$. The process is crucial for natural gas production, before being made available for transportation. For this application, membrane technology seems of a practical interest mainly due to their lower cost and footprint, higher energy efficiency and low environmental impact [4]. New strategies for developing membrane materials with improved permeation and selectivity have been described extensively, including the very promising approach of mixed matrix membranes (MMMs) [5]. MMM technology exploits the distinct and complementary properties of both polymer and inorganic materials with different physicochemical properties, selectivity and permeation flux for their selective separation.

Various materials, generally porous, such as carbon molecular sieves (CMS) [6,7], zeolites and silicas [7,8], metal oxides [9], carbon nanotubes (CNTs) [10], metal organic frameworks (MOFs) [11-14], graphene $[15,16]$, etc. have been embedded in continuous polymer

\footnotetext{
* Corresponding author.

E-mail address: coronas@unizar.es (J. Coronas).
} 
(a)

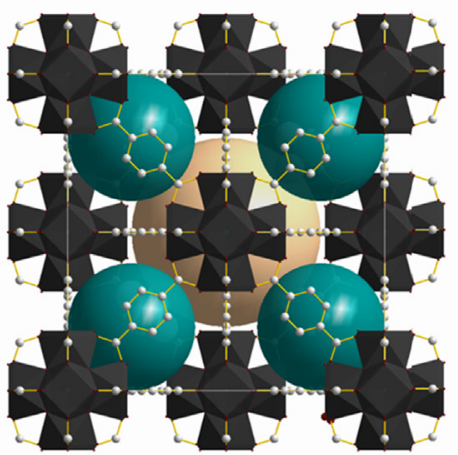

(b)

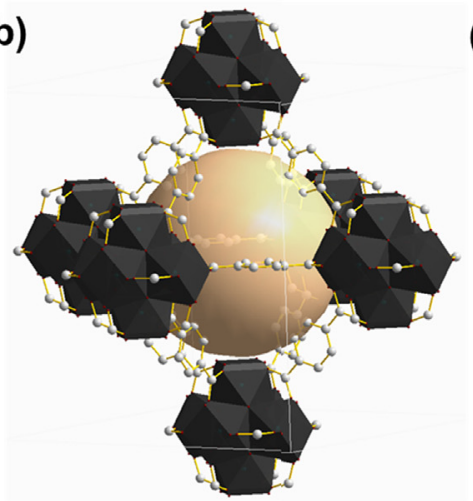

(c)

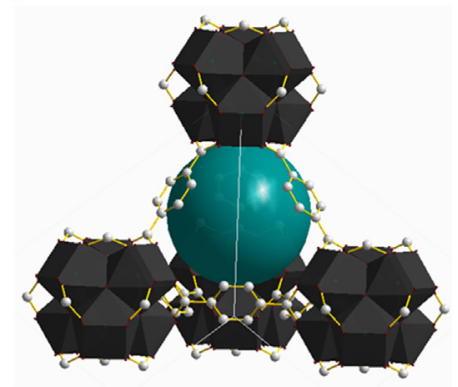

$*$ (d)<smiles>[R]c1cc(C(=O)O)ccc1C(=O)O</smiles>

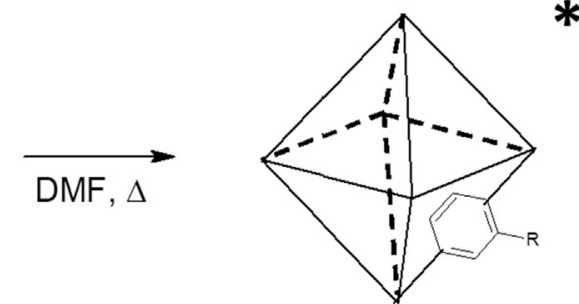

$\mathrm{R}=\mathrm{H}$ or $\mathrm{NH}_{2}$ (e)

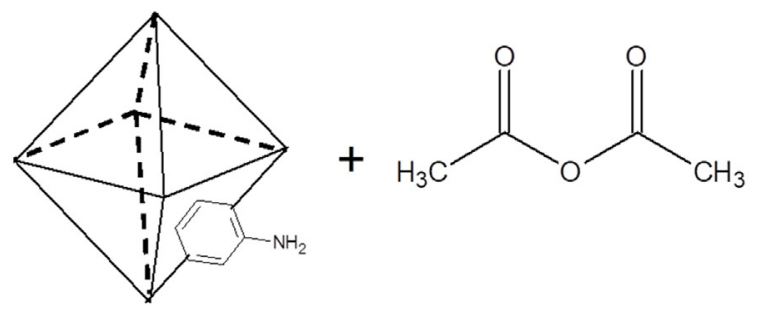

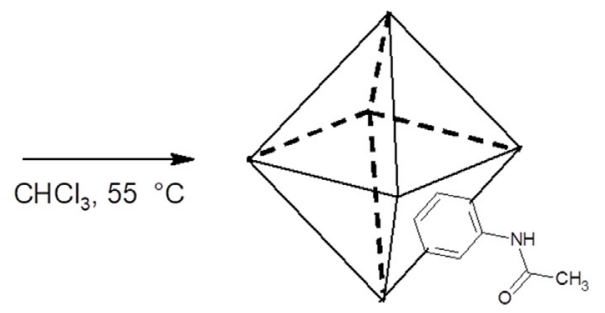

Fig. 1. Representation of the crystal structure of UiO-66, (a) the iso-reticular framework with its $\mathrm{Zr}_{6} \mathrm{O}_{6}$ cuboctahedron polyhedral (dark grey cubes), emphasizing on (b) octahedron free volume (yellow ball and also *), and (c) tetrahedron free volumes (blue ball). The drawing was done using Diamond 3.2 with CIF files obtained from CDCC open database [36]. Hydrogen atoms are omitted for ease of viewing. The reaction schemes of (d) UiO-66 and UiO-66- $\mathrm{NH}_{2}$ using $\mathrm{ZrCl}_{4}$ and $\mathrm{BDC}$ and amino-BDC, and (e) post-synthetic modification (PSM) of UiO-66- $\mathrm{NH}_{2}$ with acetic anhydride. (For interpretation of the references to color in this figure legend, the reader is referred to the web version of this article.)

matrices in the form of MMMs, thus leading to improved separation performances. The crystalline porous MOFs formed by the assembly of metal centers and organic ligands [17-21] are some of the emerging alternative fillers. They are gaining substantial attention due to their high $\mathrm{CO}_{2}$ uptake (i.e., HKUST-1 of $7.2 \mathrm{mmol} \mathrm{g}^{-1}$ [22], MOF-74 of $4.9 \mathrm{mmol} \mathrm{g}^{-1}$ [23], at $1 \mathrm{bar}, 273-298 \mathrm{~K}$ ), large surface areas up to $7000 \mathrm{~m}^{2} \mathrm{~g}^{-1}$ [24], well-defined selective pores due their crystallinity, and superior thermal and chemical stability [2], among other features. Most importantly is their tunable pore geometries and flexible frameworks [25-28], giving rise to various gas separation purposes. Indeed, MOF-containing membranes have been reported to perform better than the current Robeson upper bounds [29] for several gas pairs of great interest: $\mathrm{CO}_{2} / \mathrm{CH}_{4}$ (e.g. ZIF-90 with 6FDA-DAM [30], ZIF-8 with PIM-1 [31]), $\mathrm{CO}_{2} / \mathrm{N}_{2}$ (e.g. ZIF-7 in Pebax 1657 [32], ZIF-8 in Pebax 2533 [33]), and $\mathrm{H}_{2} / \mathrm{CO}_{2}$ (e.g. $\mathrm{NH}_{2}$-CAU-1 in PMMA [34], ZIF-8 in PBI [35]).

UiO-66 (UiO: University of Oslo), $\mathrm{Zr}_{6}\left(\mu_{3}-\mathrm{O}\right)_{4}\left(\mu_{3^{-}}\right.$ $\mathrm{OH})_{4}\left(\mathrm{O}_{2} \mathrm{C}-\mathrm{C}_{6} \mathrm{H}_{4}-\mathrm{CO}_{2}\right)_{12}$, is a highly crystalline zirconium-based MOF formed by octahedral $\mathrm{Zr}_{6} \mathrm{O}_{4}(\mathrm{OH})_{4}$, with 12 -fold connections to the organic linker 1,4-benzene-dicarboxylate (BDC) (see Fig. 1(a)) [36,37]. This microporous framework is composed of centric octahedral cages (ca. $11 \AA$, Fig. 1(b)), cornered by eight tetrahedral cages (ca. $8 \AA$, Fig. 1(c)) and trigonal window openings (ca. $6 \AA$ ). This MOF of cubic symmetry possesses a significant porosity (theoretical accessible surface of $1021 \mathrm{~m}^{2} \mathrm{~g}^{-1}$ and pore volume of $0.40 \mathrm{~cm}^{3} \mathrm{~g}^{-1}$ [38]), high resistance to heat, $\left(430-540{ }^{\circ} \mathrm{C}[37,39]\right)$, mechanical pressure and water adsorption
$[40,41]$. The $\mathrm{CO}_{2}$ uptake of UiO-66 was reported to be in the range of $1.8-2.3 \mathrm{mmol} \mathrm{g}^{-1}$ (1 bar, $298 \mathrm{~K}$ ) [42-44], while functionalization of the BDC organic ligand further increased its $\mathrm{CO}_{2}$ capacity up to $2.6 \mathrm{mmol} \mathrm{g}$ 1 with various alkanedioic acids $\left(\mathrm{HO}_{2} \mathrm{HC}\left(\mathrm{CH}_{2}\right)_{\mathrm{n}}-\mathrm{CO}_{2} \mathrm{H}\right)$ [43], $3.0 \mathrm{mmol} \mathrm{g}^{-1}$ with amino, $-\mathrm{NH}_{2}$ [42], and $2.6 \mathrm{mmol} \mathrm{g}^{-1}$ with dimethoxy, $-(\mathrm{OMe})_{2}[42]$.

UiO-66- $\mathrm{NH}_{2}$ was prepared by a direct synthesis route using amino-functionalized organic linker (UiO-66- $\mathrm{NH}_{2}=\mathrm{Zr}_{6}\left(\mu_{3}-\mathrm{O}\right)_{4}\left(\mu_{3^{-}}\right.$ $\left.\mathrm{OH})_{4}\left(\mathrm{O}_{2} \mathrm{C}-\mathrm{C}_{6} \mathrm{H}_{3}\left(\mathrm{NH}_{2}\right)-\mathrm{CO}_{2}\right)_{12}\right)$. The amino group is chemically inert in most solvents and does not participate in the coordination chemistry of the metal ions [45]. Post-synthetic modification (PSM) reactions of the amino functionality can be conducted through nucleophilic substitution, acid-base and condensation reactions [46]. This can simultaneously change the MOF properties such as pore accessibility and pore sorption behavior, depending on the orientation of the modified linkers [45]. The incorporation of functionalized-MOFs has been reported to improve the performance of the MMM compared to the pristine MOFs. As a typical illustration, Tien-Binh et al. [47] improved the $\mathrm{CO}_{2}$ permeability $\left(\mathrm{P}_{\mathrm{CO} 2}\right)$ of polyimide 6FDA-DAM-HAB $\left(\mathrm{P}_{\mathrm{CO} 2}=54\right.$ Barrer, $\left.\alpha_{\mathrm{CO} 2 / \mathrm{CH} 4}=18\right)$ by adding $10 \mathrm{wt} \% \mathrm{MIL}-53(\mathrm{Al})\left(\mathrm{P}_{\mathrm{CO} 2}=61\right.$ Barrer, $\alpha_{\mathrm{CO} 2 / \mathrm{CH} 4}=16$ ) and obtained a much higher $\mathrm{CO}_{2} / \mathrm{CH}_{4}$ selectivity with $10 \mathrm{wt} \%$ of $\mathrm{NH}_{2}-\mathrm{MIL}-53(\mathrm{Al})\left(\mathrm{P}_{\mathrm{CO} 2}=47 \mathrm{Barrer}, \alpha_{\mathrm{CO} 2 / \mathrm{CH} 4}\right.$ = 79). Anjum et al. [48] incorporated $30 \mathrm{wt} \%$ of UiO-66 and UiO-66$\mathrm{NH}_{2}$ into polyimide Matrimid 9725 and improved the $\mathrm{CO}_{2}$ permeability by $160-200 \%$. Xin et al. [49] enhanced both $\mathrm{CO}_{2}$ permeability 
of sulfonated poly (ether ether ketone), SPEEK polymer by around $100 \%$, using $40 \mathrm{wt} \%$ of MIL-101(Cr) and MIL-101(Cr)- $\mathrm{HSO}_{3}$.

Here, we synthesized $\mathrm{Zr}-\mathrm{MOF}$ UiO-66 and UiO-66- $\mathrm{NH}_{2}$ in the particle size of less than $50 \mathrm{~nm}$. UiO-66-NH-COCH $3 \quad\left(\mathrm{Zr}_{6}\left(\mu_{3}-\mathrm{O}\right)_{4}\left(\mu_{3}-\right.\right.$ $\left.\mathrm{OH})_{4}\left(\mathrm{O}_{2} \mathrm{C}-\mathrm{C}_{6} \mathrm{H}_{3}\left(\mathrm{COCH}_{3}\right)-\mathrm{CO}_{2}\right)_{12}\right)$ was obtained by acetamide-ligand PSM of UiO-66- $\mathrm{NH}_{2}$, with the aim of achieving better filler-polymer interactions, thus improving the $\mathrm{CO}_{2}$ permeability and $\mathrm{CO}_{2} / \mathrm{CH}_{4}$ separation selectivity. We carefully studied the $\mathrm{CO}_{2} / \mathrm{CH}_{4}$ gas separation enhancement of the highly permeable perfluorinated dianhydride polyimide (6FDA-DAM) and its corresponding MMMs containing 5-24 wt\% loadings of zirconium-based MOF (Zr-MOF) nanoparticles. The $\mathrm{CO}_{2}: \mathrm{CH}_{4}$ binary mixture separation was carried out more extensively than most publications using several binary compositions $\left(\mathrm{CO}_{2}=10-90 \%\right)$ and pressures up to 40 bar. Finally, we modelled the UiO-66/6FDA-DAM interface and found the existence of relatively strong interactions between certain polymer and MOF atoms associated with a moderate coverage of the UiO-66 surface by the polymer.

\section{Experimental}

\subsection{Syntheses of Zr-MOF nanoparticles (NPs)}

All reactants were supplied by Sigma-Aldrich. The UiO-66 and UiO66- $\mathrm{NH}_{2} \mathrm{NPs}$ (ca. $50 \mathrm{~nm}$ in size) were synthesized accordingly to Hou et al. [50], at 1-1 M ratio of zirconium (IV) chloride ( $\mathrm{ZrCl}_{4}, \geq 99.5 \%$ trace metal basis) to 1,4-benzenedicarboxylic acid (BDC, 98\%) or 2amino-1,4-benzenedicarboxylic acid $\left(\mathrm{NH}_{2}\right.$ - $\left.\mathrm{BDC}, 99 \%\right)$, in $\mathrm{N}, \mathrm{N}$-dimethylformamide (DMF, $\geq 99.9 \%$ ). In both preparations, $\mathrm{ZrCl}_{4}$ was first dissolved in DMF by sonication at room temperature before the addition of the corresponding organic ligand. Commonly for UiO-66 synthesis, $1.71 \mathrm{mmol}(0.40 \mathrm{~g})$ of $\mathrm{ZrCl}_{4}$ was dissolved in $100 \mathrm{~mL}$ of DMF, before the addition of equimolar BDC $(0.28 \mathrm{~g})$ and $6.84 \mathrm{mmol}(0.13 \mathrm{~mL})$ of distilled water, as a modulator to regulate the particle size [37]. Meanwhile for UiO-66- $\mathrm{NH}_{2}, 6.4 \mathrm{mmol}(1.50 \mathrm{~g}) \mathrm{ZrCl}_{4}$ and $6.4 \mathrm{mmol}$ (1.56 g) $\mathrm{NH}_{2}$-BDC were dissolved in $180 \mathrm{~mL}$ of DMF.

The solutions were later transferred into stainless steel Teflon-lined autoclaves for a solvothermal process in a pre-heated oven at $120^{\circ} \mathrm{C}$ / $24 \mathrm{~h}$ for UiO-66 and at $80^{\circ} \mathrm{C} / 14 \mathrm{~h}$ for UiO-66- $\mathrm{NH}_{2}$. A second step heating was conducted for UiO- $66-\mathrm{NH}_{2}$ at $100{ }^{\circ} \mathrm{C} / 24 \mathrm{~h}$. After cooling to room temperature, the colloidal suspensions were centrifuged at $10,000 \mathrm{rpm}$ for $15 \mathrm{~min}$. The precipitated MOF NPs were rinsed with fresh DMF $(25 \mathrm{~mL}, 3 \times)$ followed by absolute methanol $(25 \mathrm{~mL}, 3 \times)$. For each washing step, the suspension was subjected to 2-3 min sonication to re-disperse any possible agglomerates and to allow the solvent exchange. UiO-66 was activated by thermal treatment in a furnace at $300{ }^{\circ} \mathrm{C}$ for $3 \mathrm{~h}$, with a heating rate of $15^{\circ} \mathrm{C} \mathrm{min}^{-1}$. A chemical activation was conducted for UiO-66- $\mathrm{NH}_{2}$ NPs by washing in an absolute ethanol bath at $60^{\circ} \mathrm{C}$, three times for three days (ethanol was changed daily). After the complete cycle, the NPs were dried at room temperature. The reaction scheme is presented in Fig. 1(d).

\subsection{Post-synthetic modification (PSM) of UiO-66-NH}

All reactants were also supplied by Sigma-Aldrich. The synthesis of UiO-66-NH- $\mathrm{COCH}_{3}$ cannot be achieved by a direct reaction between $\mathrm{ZrCl}_{4}$ and 2-acetylamidobenzenedicarboxylic acid $\left(\mathrm{CH}_{3} \mathrm{CONH}-\mathrm{H}_{2} \mathrm{BDC}\right)$ in DMF due to the formation of an amorphous gel [51]. Thus a covalent post-synthetic modification is needed. Normally, $0.2 \mathrm{mmol}-\mathrm{NH}_{2}$ $(\sim 60 \mathrm{mg})$ was treated with a $0.2 \mathrm{mmol}$ anhydride solution $(2 \mathrm{~mL}$ chloroform $\left(\mathrm{CHCl}_{3}\right.$, anhydrous $\left.\geq 99 \%\right), 20.4 \mathrm{mg}$ acetic anhydride $\left(\mathrm{AcO}_{2}, \mathrm{ACS}\right.$ Reagent, $\left.\geq 98.0 \%\right)$ ) and heated under reflux at $55^{\circ} \mathrm{C} / 24 \mathrm{~h}$. Once completed, the colloidal solution was centrifuged, rinsed with fresh $\mathrm{CHCl}_{3}(15 \mathrm{~mL}, 3 \times)$ and dried overnight at $150^{\circ} \mathrm{C}$ before characterization and use. PSM using an acetic anhydride was reported to produce the highest conversion yield compared to the longer chain alkyl anhydrides [52], this reaction scheme is presented in Fig. 1(e).
The conversion yield was determined by the percentage of amide groups present in the modified NPs using proton nuclear magnetic resonance ( $\left({ }^{1} \mathrm{H}\right.$ NMR). Samples of $10 \mathrm{mg}$ of UiO-66- $\mathrm{NH}_{2}$ and UiO-66-NH$\mathrm{COCH}_{3}$ were digested by sonication in $570 \mu \mathrm{L}$ of deuterated dimethyl sulfoxide $\left(d_{6}\right.$-DMSO, $\geq 99.96$ atom $\left.\% \mathrm{D}\right)$ and $30 \mu \mathrm{L}$ of hydrofluoric acid (HF, 48\%), and their ${ }^{1} \mathrm{H}$ NMR spectra were acquired on a Bruker Avance III spectrometer $(500 \mathrm{MHz})$. Similar digestion method was presented elsewhere [50,52].

\subsection{Membrane fabrication}

Polymer 6FDA-DAM $(\mathrm{Mw}=418 \mathrm{kDa})$ was purchased from Akron Polymer Systems, Inc. and dried overnight at $100{ }^{\circ} \mathrm{C}$ before use. Pure polymer membranes and MMMs, in a thickness range of $100-150 \mu \mathrm{m}$, were both fabricated by dissolving the corresponding amount of 6FDADAM in chloroform, making a dope solution of $10 \mathrm{wt} \%$. For the MMMs, an amount of MOF nanoparticles was first re-dispersed in chloroform under sonication for $2 \mathrm{~h}$, followed by the addition of an initial $10-15 \%$ of the total amount of 6FDA-DAM, for priming step under vigorous magnetic-stirrer mixing. The remaining polyimide was added after 4-5 $\mathrm{h}$ of the priming step and the particle loading was calculated (Eq. (1)). The final dispersion was poured into a casting Petri dish on a leveled surface to produce flat sheet membranes. The dish was covered with a larger Petri dish for slow solvent evaporation, and the dense membrane was formed overnight at room temperature. This was followed by a treatment at $180^{\circ} \mathrm{C}$ for $24 \mathrm{~h}$ in a vacuum oven to remove the remaining solvent.

Particle loading, $\quad w t . \%=\frac{\text { Mass of filler }(g)}{\text { Mass of filler }(g)+\text { Mass of polymer }(g)} \times 100$

\subsection{Characterizations}

A scanning electron microscope (SEM) JEOL JSM 6400 operating at $20 \mathrm{kV}$ was utilized to characterize the morphology of the three Zr-MOFs and their dispersion in the membranes. The MMM cross-sections were prepared by a freeze-fracturing method using liquid $\mathrm{N}_{2}$. For easier freeze-fracturing, the membranes were first soaked in aqueous ethanol and then in liquid $\mathrm{N}_{2}$. The different NPs were also imaged by transmission electron microscopy (TEM), using an FEI Tecnai T20 operated at $200 \mathrm{kV}$. The MOF crystals were first re-dispersed in ethanol and sonicated for a few minutes, after which a couple of drops of the suspended particle solution was placed onto a holey carbon grid for the measurement.

$\mathrm{N}_{2}$ adsorption isotherms were determined using a Micromeritics Tristar 3000 porosity analyzer at $-196^{\circ} \mathrm{C}$. The BET area was calculated using the BET method $\left(P / P_{O}=0.06-0.20\right) . \mathrm{CO}_{2}$ and $\mathrm{CH}_{4}$ isotherms were obtained using an ASAP 2050 (Micromeritics), assessing Temkin and Freundlich adsorption in the $100-1000 \mathrm{kPa}$ range, at $25^{\circ} \mathrm{C}$. The samples of ca. $100 \mathrm{mg}$ were degassed at $100{ }^{\circ} \mathrm{C}$ for $8 \mathrm{~h}$ before $\mathrm{N}_{2}, \mathrm{CO}_{2}$, and $\mathrm{CH}_{4}$ adsorption measurements.

X-ray diffraction (XRD) patterns of the NPs and membranes were obtained using a PANanalytical Empyrean multipurpose diffractometer $(40 \mathrm{kV}, 20 \mathrm{~mA})$ with a $\mathrm{Cu}-\mathrm{K} \alpha(\lambda=0.1542 \mathrm{~nm})$ anode from $2 \theta$ of $2.5-40^{\circ}$ with a $0.03^{\circ}$ step s ${ }^{-1}$. Thermogravimetric analysis (TGA) was conducted on a ca. $3.5 \mathrm{mg}$ sample using a Mettler Toledo TGA equipped with simultaneous differential thermal analysis (SDTA), TGA/SDTA $851^{\mathrm{e}}$ in the air flow of $40 \mathrm{~cm}^{3}$ (STP) $\mathrm{min}^{-1}$ up to $750{ }^{\circ} \mathrm{C}$ at a heating rate of $10^{\circ} \mathrm{Cmin}^{-1}$. Decomposition temperature $\left(\mathrm{T}_{\mathrm{d}}\right)$ for the NPs was determined by maximum weight loss in their first derivative TG curves, whereas calculated at $15 \%$ weight loss for the membranes. Differential scanning calorimetry (DSC) was conducted using ca. $10 \mathrm{mg}$ sample with a Mettler Toledo DSC822e system, measured in two cycles up to $450{ }^{\circ} \mathrm{C}$ at a heating rate of $20^{\circ} \mathrm{C} \mathrm{min}{ }^{-1}$. Fourier-transform infrared spectroscopy, coupled with an attenuated total reflection (ATR-FTIR) was 
performed using a Bruker Vertex 70 spectrometer, equipped with a deuterated triglycine sulfate (DTGS) detector. The measurements were conducted from 600 to $4000 \mathrm{~cm}^{-1}$ at a resolution of $4 \mathrm{~cm}^{-1}$.

The fractional free volume of the membranes was calculated from the following equations:

$F F V=\frac{V-V_{0}}{V}=1-\quad \rho V_{0}$

$V_{0}=1.288 \times V_{v d w}$

Where $V=1 / \rho$ is the specific volume, and $V_{O}$ is the occupied volume of the polymer at $-273^{\circ} \mathrm{C}$ (Eq. (2)), estimated at 1.288 times the van der Waals volume $\left(V_{\mathrm{vdw}}\right)$ (Eq. (3)), as recently published by Horn [53]. $V_{\mathrm{vdw}}$ was calculated based on the revised Bondi's group contribution method by Park and Paul [54]. The density measurement was conducted using a pycnometer (Picnomatic Thermo) at $20^{\circ} \mathrm{C} \pm 0.01{ }^{\circ} \mathrm{C}$ where ca. $100 \mathrm{mg}$ of sample was placed in the analysis cell and degassed using $\mathrm{He}$ as the dry gas by a series of pressurization cycles from 2 to 20 bar.

\subsection{Gas separation performance}

The membranes were tested at $35{ }^{\circ} \mathrm{C}$ with a $25 / 25 \mathrm{~cm}^{3}(\mathrm{STP}) \cdot \mathrm{min}^{-1}$ $\mathrm{CO}_{2} / \mathrm{CH}_{4}$ binary mixture, with a feed pressure of 3 bar regulated together with the feed flow by mass flow controllers (Alicat Scientific, MC-5CCM-D) to maintain a pressure difference of 2 bar. He as sweep gas at $1 \mathrm{~cm}^{3}$ (STP). $\mathrm{min}^{-1}$ was used and controlled using an additional mass flow controller. The permeation module is as described elsewhere [12]. The permeate compositions were analyzed online by an Agilent 3000A micro-GC equipped with a thermal conductivity detector.

In case of high-pressure separation, a second system using a constant volume-variable pressure permeation cell with vacuum at the permeate side was used, as previously described [55]. The fresh samples were conditioned overnight in $\mathrm{N}_{2}$ at 4 bar before a continuous measurement at $35{ }^{\circ} \mathrm{C}$ with the desired $\mathrm{CO}_{2}$ and $\mathrm{CH}_{4}$ mixture (vol\%) with a feed flow of $5 \mathrm{~cm}^{3}(\mathrm{STP}) \cdot \mathrm{min}^{-1}$. Between each pressure increment, the samples were subjected to a constant $\mathrm{N}_{2}$ flow $\left(5 \mathrm{~cm}^{3}(\mathrm{STP}) \cdot \mathrm{min}^{-1}\right.$ at $\left.4 \mathrm{bar}\right)$ to eliminate the membrane history. The permeate composition was determined by direct injection into a Varian 3900 gas chromatograph (GC) using an Alltech alumina F-1 60/80 packed column bed at $150{ }^{\circ} \mathrm{C}$.

The permeability is described as the penetrated gas flux, normalized by the membrane thickness and the partial pressure drop across the membrane, and presented in Barrer (1 Barrer $=10^{-10}$ $\mathrm{cm}^{3}$ (STP) $\mathrm{cm} \mathrm{cm}^{-2} \mathrm{~s}^{-1} \mathrm{cmHg}^{-1}$ (Eq. (4)). The separation factor $(\alpha)$ of two competing gasses was calculated using Eq. (5), considering the mole fraction $(x)$ of $i$ and $j$ components in both feed and permeate streams.

Permeability, $\quad P_{\text {gas }}=\frac{\text { Flux }_{\text {gas }}\left(\mathrm{cm}^{3}(S T P) \mathrm{cm}^{-2} \mathrm{~s}^{-1}\right) \times \text { Thickness } \quad(\mathrm{cm})}{\Delta p_{\text {gas }}(\mathrm{cm} \mathrm{Hg})}$

$\alpha_{i / j}=\frac{x_{i}^{\text {perm. }} / x_{j}^{\text {perm. }}}{x_{i}^{\text {feed }} / x_{j}^{\text {feed }}}$

\subsection{Computational modelling}

The UiO-66/6FDA-DAM interface was modelled by applying a methodology which combines a MOF surface obtained by Density Functional Theory (DFT) calculations together with a flexible polymer through a series of molecular dynamics (MD) simulations [56]. The UiO-66 surface model derivation and optimization at the DFT level had been detailed elsewhere [57]. 6FDA-DAM was modelled considering a flexible force-field where the united atom approach was applied for modelling the aliphatic molecules $\left(\mathrm{CH}_{\mathrm{x}} \mathrm{x}=1,2,3\right.$ groups were considered as a single site). The bonds and angles were treated with harmonic and the dihedrals with cosine-based potential terms. Parameters were extracted from the General Amber Force Field [58]. Nonbonded interactions were modelled as a summation of 12-6 Lennard Jones potentials with parameters taken from the TraPPE force-field [59] and coulombic terms considering atomic electrostatic potential fitted (ESP) charges computed by DFT calculations on monomers, dimers and trimers using the Perdew-Burke-Ernzerhof (PBE) functional [60] (further details can be found in Supporting information). The considered polymer was modelled as a polydisperse mixture of 6 chains between 9 and 40 monomers each, built by using the Polymatic code [61]. Polydispersity makes the polymer model more realistic, as well as these results from the in-silico polymerization approach employed [61]. The effects of polydispersity on the microscopic structural features of the MOF/polymer interface were explored in a previous work for the ZIF-8/PIM-1 system and were found to be negligible [56]. Polymer and MOF were further combined through a series of 21 MD simulations spanning a total time of $1.56 \mathrm{~ns}$ to allow the polymer to adopt an optimized structure in the presence of the MOF surface. These simulations consisted of seven cycles of three simulations each, in the (i) $\mathrm{NVT}_{\max }$, $\mathrm{T}_{\max }=600 \mathrm{~K}$, (ii) $\mathrm{NVT}_{\min }, \mathrm{T}_{\min }=300 \mathrm{~K}$ and (iii) $\mathrm{NP}_{\mathrm{n}} \mathrm{T}$. Each cycle was computed at $P_{n}=1,30,50,25,5,0.5$ and 0.001 kbar, $P_{n}$ is the pressure in the direction normal to the MOF surface. The temperatures and pressures used were similar to those used in a previous work [56], and the applicability of the chosen parameters was verified concerning their validity for the pure 6FDA-DAM equilibration, which was assessed by comparing density and X-ray pattern of the model polymer with experimental values. Data for the structural analysis were collected from $10 \mathrm{MD}$ runs (10 ns long each run) and with a time-step of $1 \mathrm{fs}$, using Berendsen thermostat and barostat [62] with relaxation times of 0.1 and $0.5 \mathrm{ps}$, respectively. These runs differ in the starting configuration, and the objective of performing 10 of them was to reproduce, in average, the results that would be obtained from a biased potential dynamics that would allow for a full sampling of the flat energy surface [56]. Polymatic uses LAMMPS [63] as MD engine. The rest of the MD simulations were performed with a modified version of DLPOLY Classic $[64,65]$. Further details are given in the Supporting information.

\section{Results and discussion}

\subsection{MOF characterization}

All the Zr-MOFs were found to be in a size range of below $50 \mathrm{~nm}$, as shown in the corresponding TEM images (Fig. 2), where their distinctive cubic morphologies can be observed. Their small size makes these NPs suitable fillers for preparing thin and homogenous MMMs [66]. XRD patterns in Fig. 3(a) demonstrate the high crystallinity of the Zr-MOFs obtained after the activation treatment. Also, their corresponding XRD patterns are in good agreement with the simulated pattern for UiO-66 crystal structure [37]. It should be noted that the introduction of amine and amide groups into UiO-66 has a negligible influence on the crystal structure. The three Zr-MOF crystallite sizes estimated using Scherrer equation [67] were in the average of about $40 \mathrm{~nm}$, in good agreement with TEM results.

Fig. 3(b) shows the weight loss curves of the Zr-MOFs where the first drop below $100^{\circ} \mathrm{C}$ corresponds to the loss of remains of solvent. The next drop until $300{ }^{\circ} \mathrm{C}$ corresponds to the dehydration of the $\mathrm{Zr}_{6} \mathrm{O}_{4}(\mathrm{OH})_{4}$ nodes to $\mathrm{Zr}_{6} \mathrm{O}_{6}$ [68]. The following drop up to $500-550{ }^{\circ} \mathrm{C}$ is related to the decomposition of organic linkers before oxidation into $\mathrm{ZrO}_{2}[37,42]$, and the higher mass losses observed in the functionalized UiO-66 NPs are due to their higher organic linker molecular masses. The MOF structure at the second stage is $\mathrm{Zr}_{6} \mathrm{O}_{6} \mathrm{~L}_{x}(\mathrm{~L}=\mathrm{BDC}$ or BDC-NH or BDC-NH-COCH $3, x=1-6$ ), and $x$-L indicates the amount of the particular ligand present in the framework [68]. The as-synthesized UiO-66 calculated to have 4-ligand with $2.1 \%$ missing organic linkers for every $\mathrm{Zr}$ atom [13], comparing to the simulated 4-ligand UiO-66 [68]. The decomposition temperatures $\left(\mathrm{T}_{\mathrm{d}}\right.$, from the corresponding 

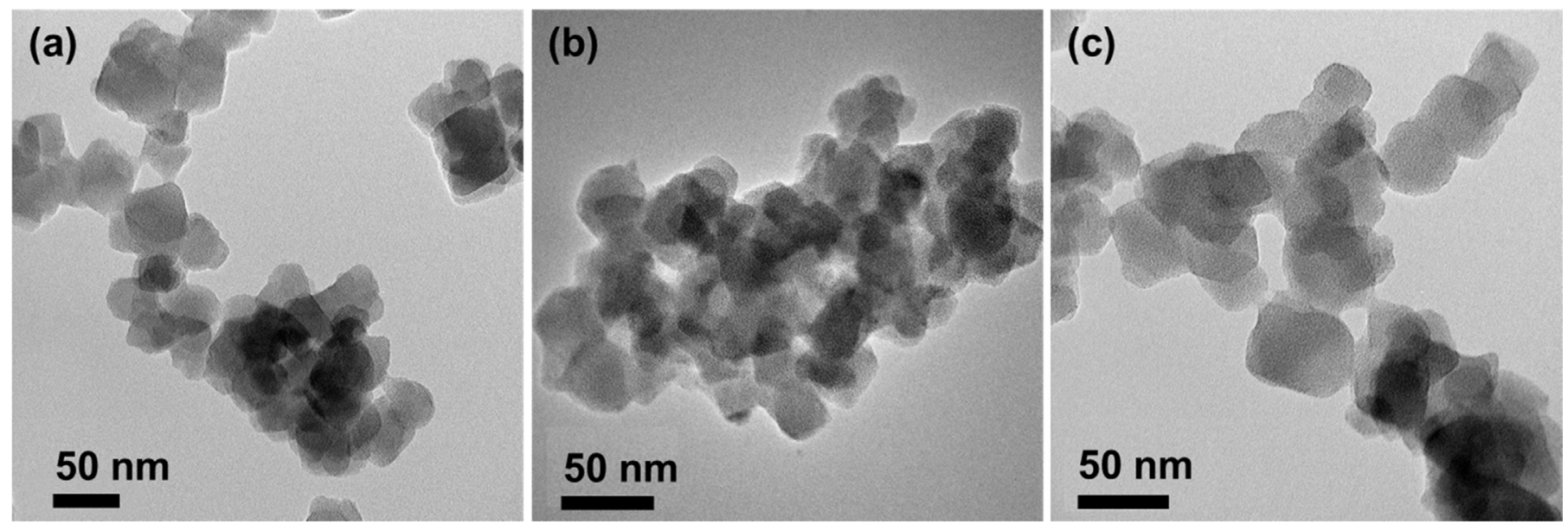

Fig. 2. TEM images of (a) UiO-66, (b) UiO-66- $\mathrm{NH}_{2}$ and (c) the modified UiO-66-NH-COCH 3 .

derivative maxima in Fig. 3(b)) of the Zr-MOFs confirm their high thermal stability in the range of $430-540{ }^{\circ} \mathrm{C}[37,39,69]$ : UiO$66=542{ }^{\circ} \mathrm{C}$, UiO-66- $\mathrm{NH}_{2}=452^{\circ} \mathrm{C}$ and UiO-66-NH-COCH ${ }_{3}=437^{\circ} \mathrm{C}$.

Fig. S1(a) shows the FTIR spectra of the Zr-MOFs, indicating their characteristic peaks and the discussion is presented accordingly in the Supporting Information. The degree of PSM conversion of aminofunctionalized UiO-66 to acetamide was determined by ${ }^{1} \mathrm{H}$ NMR, where the distinct downfield shift of $\mathrm{C}_{2}$-position aromatic proton associated with the BDC ligand was calculated (Fig. S2). From the relative integration of these aromatic resonances between unmodified and modified UiO-66- $\mathrm{NH}_{2}$, we estimated an amide yield of $54.5 \pm 3.5 \%$ (average of two different experiments) after a $24 \mathrm{~h}$ reaction at $55^{\circ} \mathrm{C}$, lower than the reported yield of $88 \%$ for the same reaction period [52] (with a starting UiO-66- $\mathrm{NH}_{2}$ material of unknown particle size and having $1112 \mathrm{~m}^{2} / \mathrm{g}$ instead of ours $965 \mathrm{~m}^{2} / \mathrm{g}$ ). The successful amine to amide conversion can also be observed by the additional - $\mathrm{NH}-$ peak at $9 \mathrm{ppm}$ which only appears in the modified UiO-66- $\mathrm{NH}_{2}$. Kandiah et al. [51] reported a $100 \%$ conversion of UiO-66- $\mathrm{NH}_{2}$ with acetic anhydride, on the $14^{\text {th }}$ day of reaction at room temperature. The PSM reaction conversion is highly dependent on the reaction conditions (and for our study we did not further optimize the PSM conditions), without ruling out other effects related to textural properties. However, we believe our conversion level gave rise to functionalization enough to enhance both the filler-polymer interaction and the membrane $\mathrm{CO}_{2}$ interaction regarding $\mathrm{CO}_{2} / \mathrm{CH}_{4}$ separation, both are discussed in Section 3.2 and Section 3.4.
The BET specific surface areas of the activated Zr-MOFs are (Table S1): UiO-66 $=951 \mathrm{~m}^{2} \mathrm{~g}^{-1}$, UiO-66- $\mathrm{NH}_{2}=965 \mathrm{~m}^{2} \mathrm{~g}^{-1}$ and UiO-66-NH$\mathrm{COCH}_{3}=913 \mathrm{~m}^{2} \mathrm{~g}^{-1}$. These values are consistent with the data previously reported for UiO-66 type materials [38]. Fig. S3 shows the $\mathrm{N}_{2}$ adsorption and desorption isotherms of the $\mathrm{Zr}$-MOFs obtained at $77 \mathrm{~K}$. A combination of types I and IV isotherms is suggested in all samples. The presence of type IV isotherm is often due to capillary condensation between the smaller nanoparticles [13] and started to occur in our $\mathrm{Zr}$ MOFs in the range of $P / P_{o}=0.5-0.8$. No hysteresis was observed in larger particle sizes, e.g., $60-80 \mathrm{~nm}$ UiO-66 [70] and ca. $200 \mathrm{~nm} \mathrm{UiO-}$ $66-\mathrm{NH}_{2}$ [71]. We found that the amino moieties did not have much effect on the UiO-66 system porosity, as similarly observed in several publications [52,70,72]. A larger functional group (e.g., $\mathrm{Br},-\mathrm{NO}_{2}$, Naph [52]), however, does reduce the porosities. In agreement to this, the acetamide-PSM UiO-66-NH- $\mathrm{COCH}_{3}$ presented the lowest BET specific surface area and possibly due to our lower conversion; it is still higher than the previously reported value of $818 \mathrm{~m}^{2} \mathrm{~g}^{-1}$ [52]. The consistent micropore volume values of $0.32-0.35 \mathrm{~cm}^{3} \mathrm{~g}^{-1}$ for the $\mathrm{Zr}$ MOFs, indicated no significant blockage of the pore system by the UiO66 functionalization.

Fig. 4(a) and (b) show the $\mathrm{CO}_{2}$, and $\mathrm{CH}_{4}$ adsorption isotherms of the Zr-MOFs measured at $25^{\circ} \mathrm{C}$ between 0.1 and 10 bar and their resultant gas uptakes up to 1 bar. Table S2 presents the gas uptake values, corresponding to Fig. 4(b). The UiO-66 functionalization increased the $\mathrm{CO}_{2}$-philicity, as expected. $\mathrm{CO}_{2}$ adsorption capacities at are in the following order (Table S2 at 1 bar and $\left.25^{\circ} \mathrm{C}\right)$ : UiO-66- $\mathrm{NH}_{2}(1.79 \mathrm{mmol}$ (a)

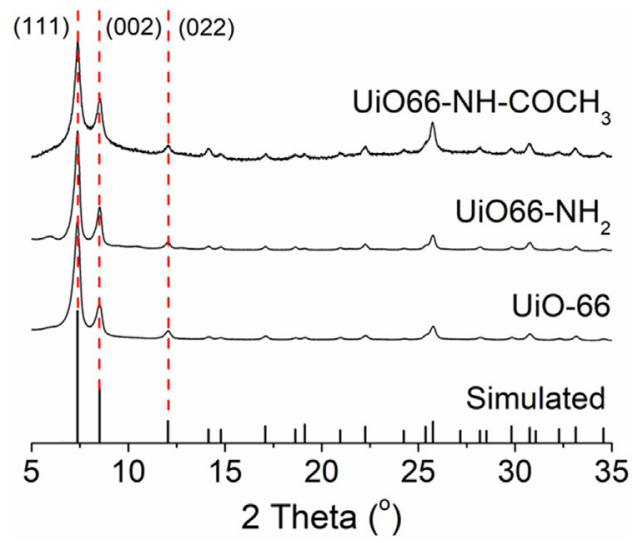

(b)

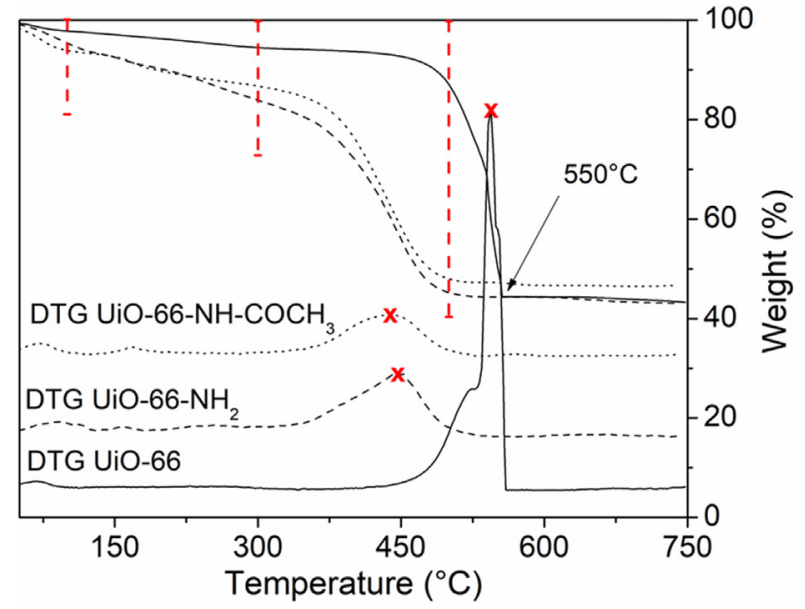

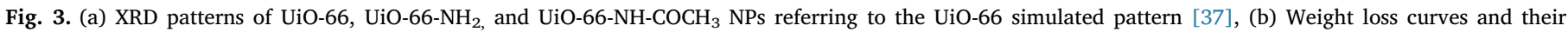
corresponding derivatives for the Zr-MOFs, obtained from TGA. Vertical dotted lines indicate the weight losses at discussed temperatures for ease of viewing. 
(a)

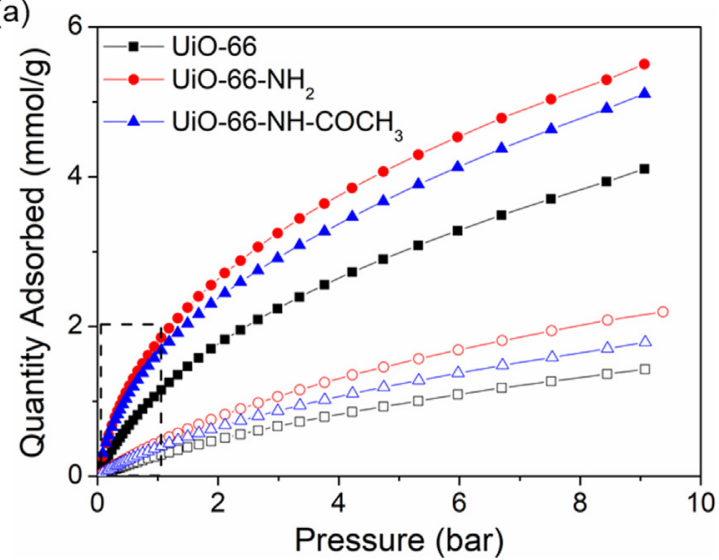

(b)

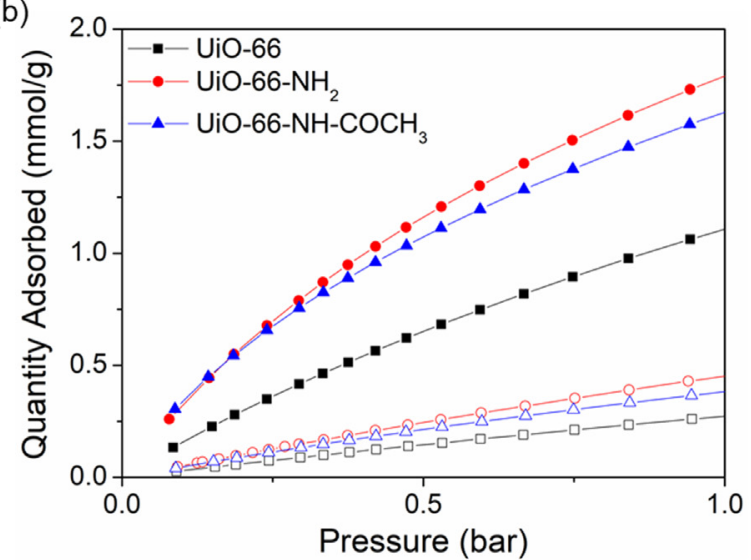

Fig. 4. $\mathrm{CO}_{2}$ (filled symbols) and $\mathrm{CH}_{4}$ (empty symbols) isotherms, at (a) high pressure, $0.1-10$ bar and (b) low pressure, $0.1-1.0$ bar, measured at $25^{\circ} \mathrm{C}$.

$\left.\mathrm{g}^{-1}\right)>$ UiO-66-NH-COCH 3 (1.63 mmol g-1) $>$ UiO-66 $\left(1.13 \mathrm{mmol} \mathrm{g}^{-}\right.$ $\left.{ }^{1}\right)$. The slightly lower adsorption capacities than the reported values (1.8-2.3 $\left.\mathrm{mmol} \mathrm{CO}_{2} \mathrm{~g}^{-1}\right)$ measured under the same conditions [42-44] can be due to the different activation methods used. At a higher activation temperature $\left(>250^{\circ} \mathrm{C}\right)$, de-hydroxylated UiO-66 is produced resulting in lower adsorbing UiO-66 [13,73]. The interaction between the framework pore affinity and the adsorbates $\left(\mathrm{CO}_{2}, \mathrm{CH}_{4}\right)$ greatly determines the capacity of the adsorption. The presence of an additional oxygen heteroatom in UiO-66- $\mathrm{NH}-\mathrm{COCH}_{3}$ increases the amide group polarity, thus making it more carbon-electron deficient. The amide group is more nucleophilic than the amine group and therefore expected to interact more strongly with $\mathrm{CO}_{2}$. The slightly lower $\mathrm{CO}_{2}$ adsorption capacity for UiO-66-NH- $\mathrm{COCH}_{3}$ vs. its amino form $\left(1.63 \mathrm{mmol} \mathrm{g}^{-1}\right.$ vs. $1.79 \mathrm{mmol} \mathrm{g}^{-1}$ ) is due to the higher steric hindrance created by the bulkier functional groups thus restricting $\mathrm{CO}_{2}$ access to the porosity.

\subsection{Membrane characterization}

XRD and FTIR spectroscopy were used to determine any possible chemical interaction between the MOFs and polymer, while the flat sheet MMM microstructures (thickness of 100-150 $\mu \mathrm{m}$ ) were imaged by SEM. Referring to the XRD patterns in Fig. 5(a), the pristine 6FDA-DAM shows a broad peak characteristic of an amorphous polymer with a $d$ spacing of $7.0 \AA$. The Zr-MOFs maintained their crystallinity in the polymer matrix, based on the comparison of MMM XRD patterns with

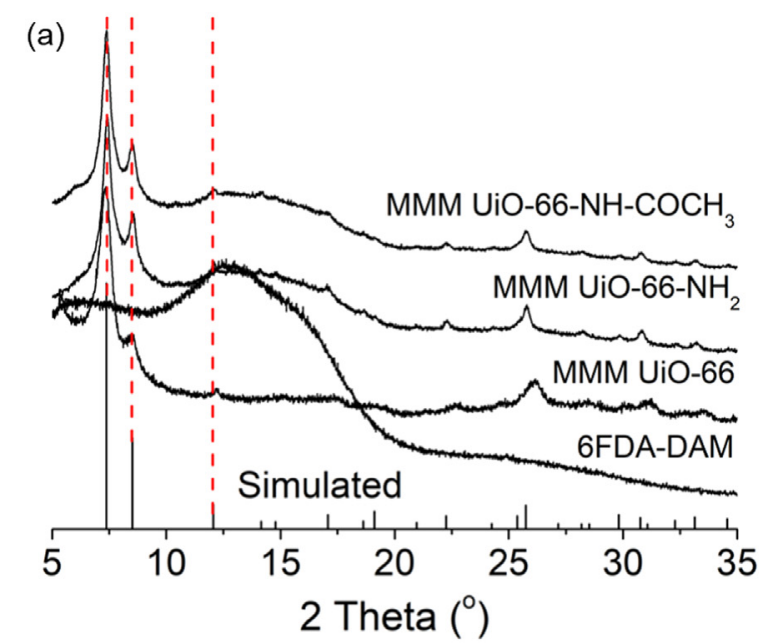

UiO-66 characteristic diffraction peaks [37]. We found no evidence that the incorporation of functionalized UiO-66 altered the polymer $d$-spacing. In fact, this could occur due to polymer interpenetration into the NPs framework as previously reported in PEBA with UiO-66- $\mathrm{NH}_{2}$ [70], and in 6FDA-DAM with mesoporous silica and hollow zeolite particles [74].

Additionally, FTIR absorbance of pristine 6FDA-DAM presented in Fig. 5(b) indicates the presence of the key functional group signals in diamine moiety. The symmetric $-\mathrm{C}=\mathrm{O}$ stretching at $1720 \mathrm{~cm}^{-1}$ and the imide -C-N- at $1373 \mathrm{~cm}^{-1}$, remained unchanged. The spectra show no new peaks, suggesting no strong chemical interaction between the MOF NPs and 6FDA-DAM. Nonetheless, a dominant presence of hydrogen bonding in the functionalized-MOF MMMs, in the following order; UiO66-NH- $\mathrm{COCH}_{3}>$ UiO-66- $\mathrm{NH}_{2}>$ UiO-66 may have lessened filler agglomeration and improved MOF NPs-polymer interaction. The influence of hydrogen bonding can be observed in FTIR spectra (Fig. S4), where upward shifts of the polymer carbonyl group by $3 \mathrm{~cm}^{-1}$ were found in both functionalized-MOF MMMs indicating hydrogen bond interaction [75]. Their corresponding SEM images (Fig. S5) show smaller (up to ca. $500 \mathrm{~nm}$, observed for 6-24 wt\% loading MMMs) and more uniform agglomerates compared to those of UiO-66 MMMs (ca. $200-600 \mathrm{~nm}$, between the lowest loading $4 \mathrm{wt} \%$ to the highest $21 \mathrm{wt} \%$ ). This is due to the presence of an additional hydrogen donor/acceptor moieties $\left(-\mathrm{NH}_{2}\right.$ and $\left.-\mathrm{NHCOCH}_{3}\right)$ in the functionalized $\mathrm{Zr}-\mathrm{MOFs}$, forming the intermolecular hydrogen bond with 6FDA-DAM bond/acceptor $\left(-\mathrm{CF}_{3}\right)$ and donor/acceptor $(-\mathrm{C}=\mathrm{O}$ and $-\mathrm{CN}-)$.

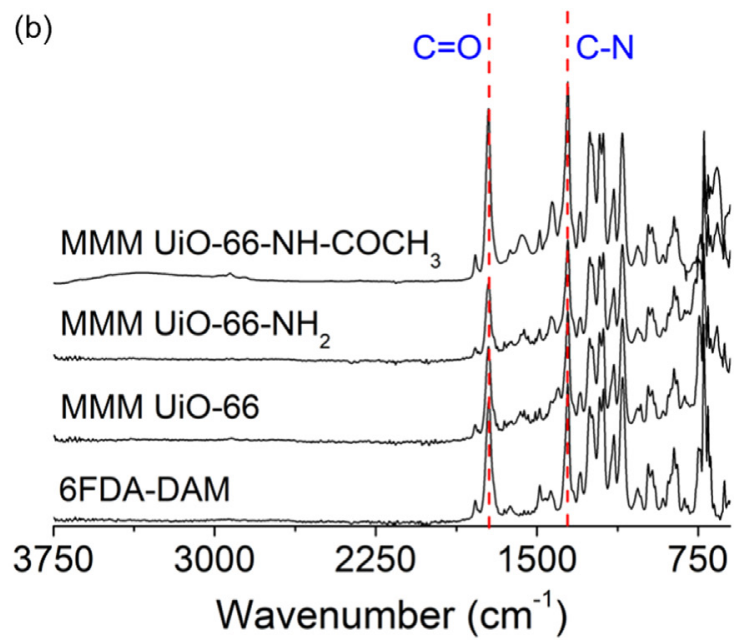

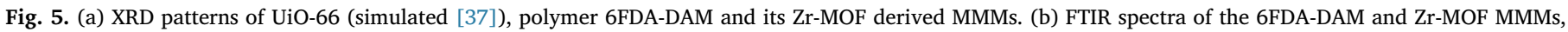
with $14-16 \mathrm{wt} \%$ of particle loadings. 
Table 1

The glass transition temperature $\left(\mathrm{T}_{\mathrm{g}}\right)$, decomposition temperature $\left(\mathrm{T}_{\mathrm{d}}\right)$, calculated at $15 \%$ weight loss, solid density and free fractional value (FFV) values of the neat 6FDA-DAM and the respective Zr-MOF MMMs.

\begin{tabular}{llllll}
\hline \multirow{2}{*}{ Membrane } & $\begin{array}{l}\text { Particle loading } \\
(\mathbf{w t} \%)\end{array}$ & \multicolumn{4}{l}{ Physical properties } \\
\cline { 3 - 6 } & & $\mathbf{T}_{\mathbf{g}}\left({ }^{\circ} \mathbf{C}\right)$ & $\mathbf{T}_{\mathbf{d}}\left({ }^{\circ} \mathbf{C}\right)$ & Density $^{\mathrm{a}}$ & FFV $^{\mathrm{b}}$ \\
\hline 6FDA-DAM & - & 396 & 522 & 1.259 & 0.238 \\
$\mathrm{UiO}-66 \mathrm{MMM}$ & 8 & 395 & 525 & 1.188 & 0.281 \\
& 21 & 405 & 523 & 1.106 & 0.331 \\
$\mathrm{UiO}-66-\mathrm{NH}_{2} \mathrm{MMM}$ & 6 & 398 & 527 & 1.237 & 0.251 \\
$\mathrm{UiO}-66-\mathrm{NH}-\mathrm{COCH}_{3}$ & 16 & 409 & 522 & 1.195 & 0.277 \\
$\mathrm{MMM}$ & 6 & 399 & 536 & 1.299 & 0.214 \\
& 16 & 413 & 530 & 1.170 & 0.292
\end{tabular}

a Density for MMMs was normalized to the actual MOF loadings.

b FFV was calculated from the solid densities measured at $20^{\circ} \mathrm{C}$ with pressurized He cycles between 2 and 20 bar.

DSC measurements (Table 1) showed that the as-purchased 6FDADAM transitioned to a rubbery polymer at $396^{\circ} \mathrm{C}$ (glass transition temperature, $\mathrm{T}_{\mathrm{g}}$ ), close to the reported data at $372-395{ }^{\circ} \mathrm{C}$ [76-78]. The $\mathrm{T}_{\mathrm{g}}$ increased by less than $10^{\circ} \mathrm{C}$ in UiO-66 MMMs and by slightly more than $10{ }^{\circ} \mathrm{C}$ and around $20^{\circ} \mathrm{C}$ in UiO-66- $\mathrm{NH}_{2}$ and UiO-66-NH- $\mathrm{COCH}_{3}$ MMMs, respectively. In general, the inclusion of the MOF filler shows excellent interphase adhesion, indicated by the filler-polymer stretched delamination segments (see Fig. S5). It also causes rigidification of polymer chains, thus limiting their movement and increasing the corresponding $\mathrm{T}_{\mathrm{g}}$ values. MMM thermal stabilities were characterized by TGA, and the corresponding decomposition temperature $\left(\mathrm{T}_{\mathrm{d}}\right)$ values were calculated at $15 \%$ membrane weight loss (Fig. S6 and Table 1). As expected, the $\mathrm{T}_{\mathrm{d}}$ changes were less substantial at lower loadings. The changes were most prominent in UiO-66- $\mathrm{NH}-\mathrm{COCH}_{3} \mathrm{MMMs}$ due to the higher possibility of the hydrogen bonding to occur, leading to a stronger intermolecular interaction, as previously discussed. There were no remarkable differences in the UiO-66 and UiO-66- $\mathrm{NH}_{2} \mathrm{MMMs}$ $\mathrm{T}_{\mathrm{d}}$ values compared to that of the pure 6FDA-DAM $\left(\mathrm{T}_{\mathrm{d}}\right.$, pure $\left.=522^{\circ} \mathrm{C}\right)$. The UiO-66-NH-COCH 3 MMMs $\left(\mathrm{T}_{\mathrm{d}}=530^{\circ} \mathrm{C}\right)$, however, show $\mathrm{T}_{\mathrm{d}}$ increment of around $8^{\circ} \mathrm{C}$. Regarding solid densities and FFV values, it is important to note that the MMM densities were measured and normalized to the actual loadings of Zr-MOFs, obtained from TGA analysis. The neat membrane showed a FFV of 0.238 , higher than the 6FDA-DAM reported values in the $0.181-0.190$ interval $[76,77,79]$, and in the upper range of most polymers $(\mathrm{FFV}=0.1-0.3)[54,80]$.

\subsection{Modelling of the UiO-66/6FDA-DAM interface}

The UiO-66/6FDA-DAM interface was modelled to obtain information regarding its microscopic structure. The interfacial polymer accommodates in such a way that it forms a network of interconnected micro-voids in the region closest to the MOF surface (see a typical snapshot in Fig. 6(a)). Furthermore, no polymer penetration into the UiO-66 open pores was observed, in agreement to the previously discussed XRD analysis. Fig. 6(b) shows that there is a partial overlap between the atomic density of the polymer and that of the MOF in region $\boldsymbol{A}$, corresponding to the interface closest region. As we move away from the MOF surface, the density of the polymer increases almost linearly (marked as region $\boldsymbol{A}$ in the plot), up to a point where it exhibits large oscillations (region B). Region $\boldsymbol{A}$ was found to extend up to $8 \AA$ from the MOF surface, while the full extension of region $\boldsymbol{B}$ cannot be determined from these simulations. Indeed, it has been shown that the polymer starts behaving as bulk polymer at distances 2-3 times its gyration radius from the MOF surface, which would imply a system too large to be tractable in an atomistic model [81].

The void sizes in regions $\boldsymbol{A}$ and $\boldsymbol{B}$ were further investigated by two different methodologies. The first one is the $v_{-}$connect method [82], (a)
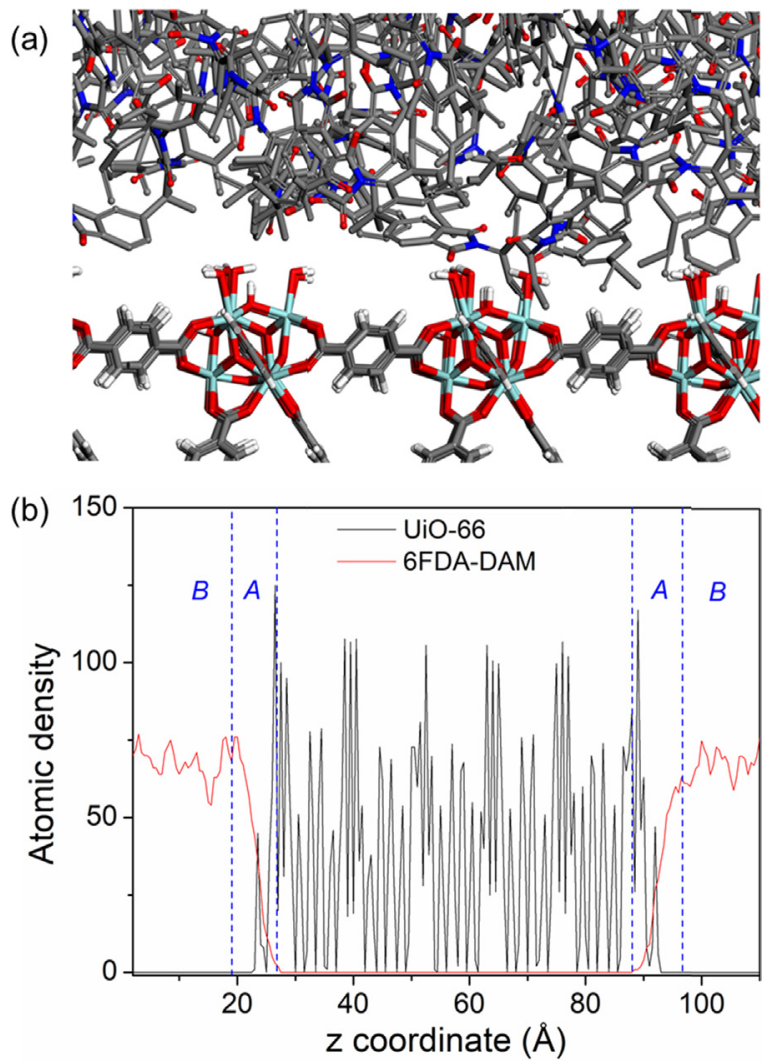

Fig. 6. (a) Zoom into a typical snapshot of the UiO-66/6FDA-DAM model interface. Color code: $\mathrm{CH}_{\mathrm{x}}$ (grey, $\mathrm{x}=0,1,2,3$ ), $\mathrm{N}$ (blue), $\mathrm{H}$ (white), $\mathrm{O}$ (red) and $\mathrm{Zr}$ (light blue). (b) Atomic density profile for the polymer (red line) and the MOF (black line) along the direction perpendicular to the MOF surface ( $\mathrm{z}$ coordinate). (For interpretation of the references to color in this figure legend, the reader is referred to the web version of this article.)

which consists of dividing the space with a three-dimensional grid, classifying the cubes as empty or filled, and then probing the empty cubes with a probe of defined size. The chosen probe has a 1.1 A radius, which has been shown to give results that are comparable to those obtained with Positron Annihilation Lifetime Spectroscopy (PALS) experiments [82]. The second methodology consists of defining the pore size distribution considering the maximum radius of a sphere that can be fitted inside the pore at a given point in space [83]. Results for these analyses are shown in Fig. S7. The top and middle panels come from applying the $v_{-}$connect method, while the bottom panels show the pore size distribution according to Bhattacharya and Gubbins. From the latter, the largest voids at region $\boldsymbol{A}$ were found to have a diameter of $7 \AA$, while slightly smaller (up to $5 \AA$ ) in region $B$. Pore number and free volume fraction values as a function of the pore size obtained by the $v_{-}$connect method show pores of up to 10 and $12 \AA$ diameters in regions $\boldsymbol{A}$ and $\boldsymbol{B}$ respectively, much larger than those observed with the Bhattacharya method. This means that the voids deviate from a spherical shape and they are interconnected between each other [56,82].

Radial distribution functions between the 6FDA-DAM functional groups and the $\mathrm{OH}$ terminations of UiO- 66 were computed to reveal the preferential site-to-site intermolecular interactions. It was found that 6FDA-DAM methyl and carbonyl groups interacted with the UiO-66 OH terminations, with characteristic distances of 3.2 and $1.6 \AA$, respectively (see the first peaks in the radial distribution functions in Fig. 7). The latter short MOF/polymer distance was associated with a relatively strong interaction between the MOF and the polymer.

Recently, a study classifying the compatibility of composites formed by different polymers with UiO-66 as a filler was published [57]. The selected UiO-66/polymer composites were found to belong to one of 
(a)

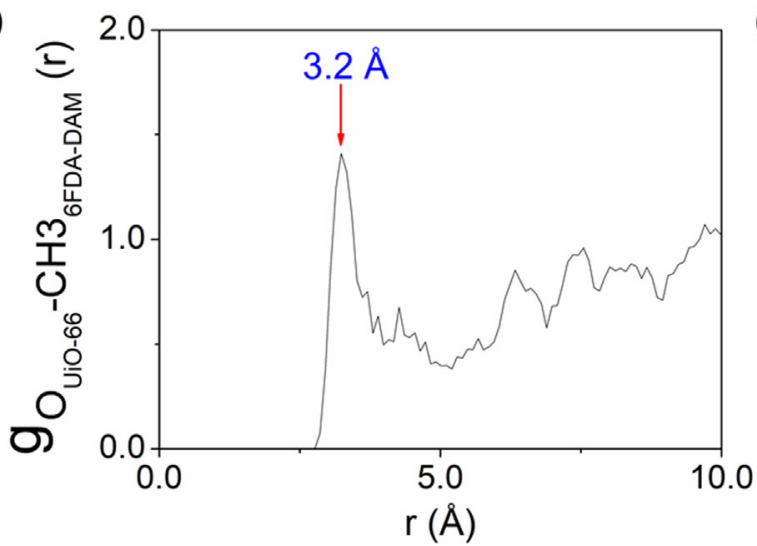

(b)

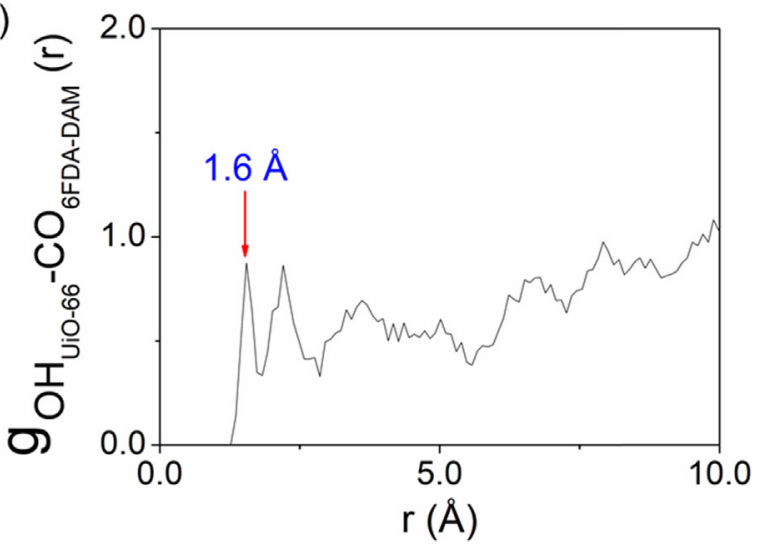

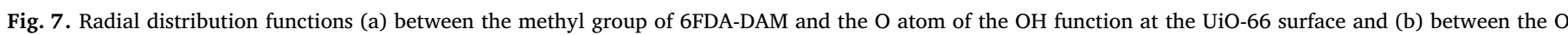
atom of the carbonyl group of 6FDA-DAM and the $\mathrm{H}$ atom of the $\mathrm{OH}$ function at the UiO-66 surface.

two groups with respect to their microscopic characteristics: either the polymer adapts its structure to the morphology offered by the MOF and can even penetrate into the MOF open pores (e.g., polyethylene glycol and polyvinylidene fluoride), or the polymer structure rigidifies and forms microvoids at the interface (e.g., polymer of intrinsic microporosity, PIM-1, and polystyrene). The microscopic scenario described for the UiO-66/6FDA-DAM interface is reminiscent of the second composite group, which exhibited a moderate MOF/polymer compatibility. Further insight can be gained by comparing the surface coverage between the different composites and achieved by computing several microscopic parameters for coverage quantification [57]. These are the previously mentioned extension of region $\boldsymbol{A}$, the atomic density of the polymer in the region where it coexists with the MOF, $\rho_{s}$, and its normalized value with respect to the polymer bulk density, $\lambda_{s}$. The obtained values for 6FDA-DAM were computed and compared to those of previously studied MOF/polymer pairs (see Table S3). Results show the UiO-66/6FDA-DAM composite is an intermediate case between the UiO-66/polystyrene and UiO-66/PIM-1 composites. It shares a similar

\section{(a)}

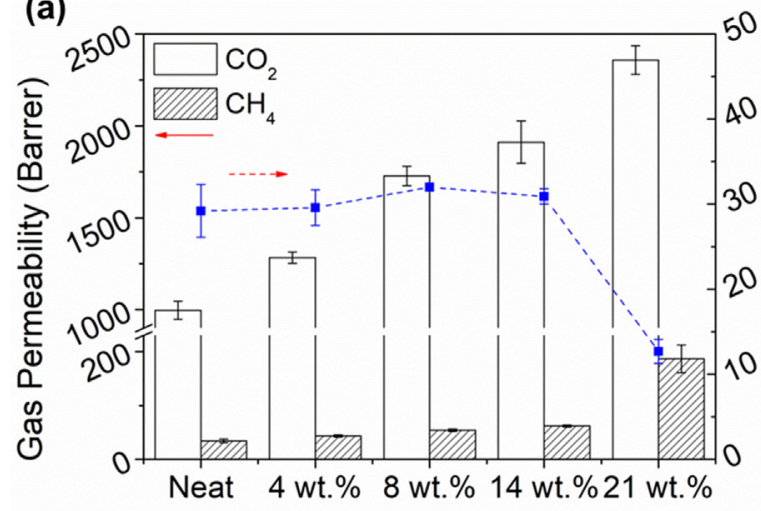

(c)

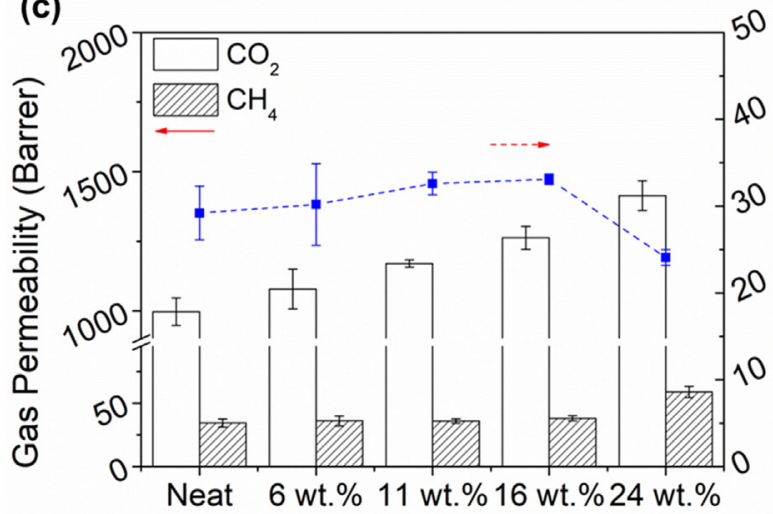

(b)

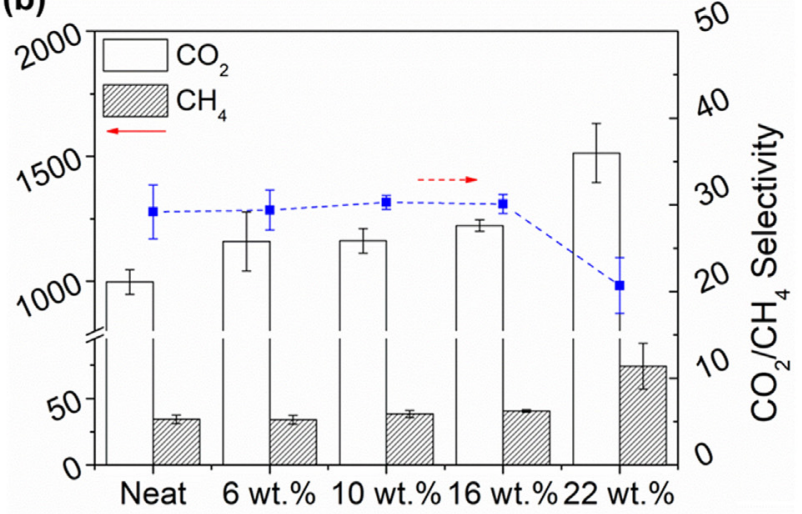

(d)

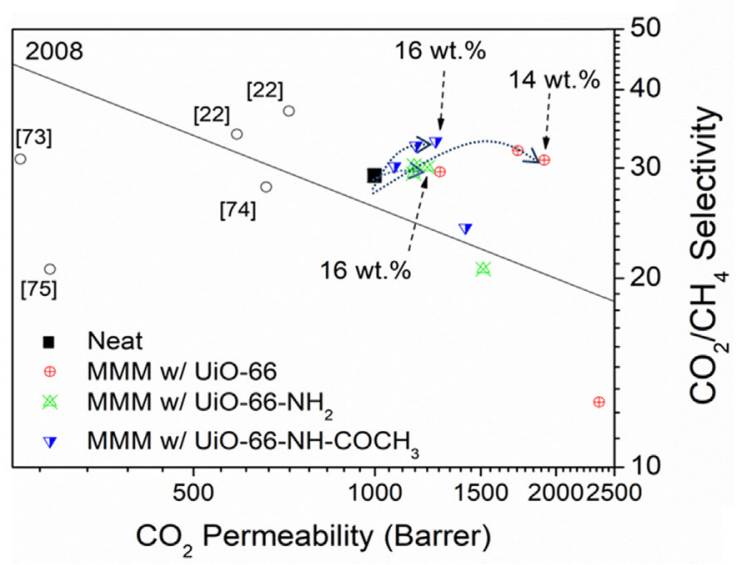

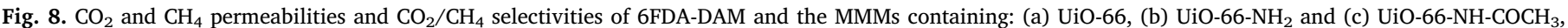

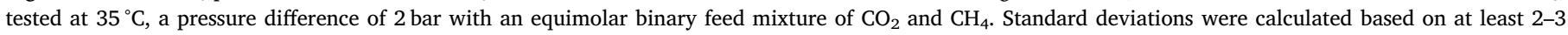

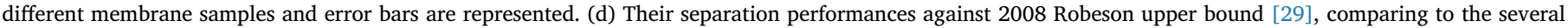

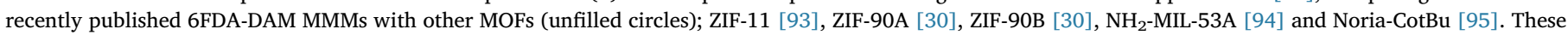

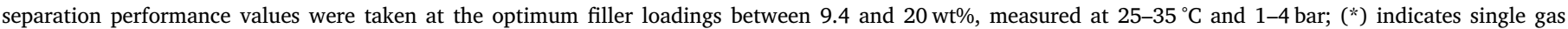
permeation and its ideal selectivity; and (**) indicates binary $\mathrm{CO}_{2}: \mathrm{CH}_{4}$ mixture measurement at 1:1 vol ratio. 
extension of the region $\boldsymbol{A}$ with the polystyrene-based MMM, but the 6FDA-DAM atomic density in the closest proximity of the MOF is close to that observed of the PIM-1 composite. The normalized density value shows that the polymer density in this region is only $20 \%$ of that the bulk polymer. Altogether, these results emphasize a moderate surface coverage of UiO-66 by 6FDA-DAM which was revealed not to be a drawback for the membrane performances with regard to gas separation, as presented. In fact, an excellent MOF/polymer compatibility is expected to allow for an easy membrane preparation or manufacturing, which however might be at the expense of the MOF pore partial blockage, which can have a detrimental effect on the selectivity or permeability of the composite, as exhibited by the UiO-66/polyethylene glycol case [57].

\subsection{Gas transport properties}

\subsubsection{Mixed gas separation performances}

Fig. 8(a-c) and Table S4 show the gas separation performances of 6FDA-DAM and its Zr-MOF MMMs, with different wt $\%$ loadings. The 6FDA-DAM neat membrane presented a higher $\mathrm{CO}_{2}$ permeability and $\mathrm{CO}_{2} / \mathrm{CH}_{4}$ selectivity values $\left(\mathrm{P}_{\mathrm{CO} 2}=997\right.$ Barrer, $\left.\alpha_{\mathrm{CO} 2 / \mathrm{CH} 4}=29.2\right)$ than those recently reported with the same polymer [74,77]. This may be attributed to a few factors, such as higher polymer molecular weight $\left(\mathrm{M}_{\mathrm{w}}=418 \mathrm{kDa}\right)$, higher free fractional volume $(\mathrm{FFV}=0.24)$ and different post-treatment temperatures (at $180^{\circ} \mathrm{C}$ ). In fact, Zornoza et al. [74] reported $\mathrm{P}_{\mathrm{CO} 2}=681$ Barrer and $\alpha_{\mathrm{CO} 2 / \mathrm{CH} 4}=21.4$ for membranes prepared from 6FDA-DAM with $\mathrm{M}_{\mathrm{w}}=81 \mathrm{kDa}$ and FFV $=0.19$, treated at the same temperature. Yeom et al. [77] reported $\mathrm{P}_{\mathrm{CO} 2}=467$ Barrer and $\alpha_{\mathrm{CO} 2 / \mathrm{CH} 4}=15.9$, prepared from 6FDA-DAM with FFV $=0.18$ and treated at $250^{\circ} \mathrm{C}$. FFV is a well-established factor that plays a major role in governing gas diffusivity within the polymer matrix [80]. Moreover, a higher annealing temperature produces a denser membrane thus affecting its free volume cavities and gas separation properties [84]. Several studied reported notable gas separation enhancement by optimizing the membrane thermal annealing procedure [85-87], optimizing the charge-transfer complex (CTC) phenomenon in aromatic polyimides, an inter- and intramolecular interaction which occurs more prominently at a high temperature $[88,89]$.

In this study, the best performing 6FDA-DAM MMMs are with 14 $16 \mathrm{wt} \%$ Zr-MOF loadings. $14 \mathrm{wt} \%$ UiO-66 and $16 \mathrm{wt} \%$ UiO- $66-\mathrm{NH}_{2}$ improved $\mathrm{CO}_{2}$ permeability of 6 FDA-DAM by $92 \%$ and $23 \%$, respectively, while maintaining the $\mathrm{CO}_{2} / \mathrm{CH}_{4}$ selectivity at $\sim 30$. The addition of $16 \mathrm{wt} \%$ of UiO-66-NH-COCH${ }_{3}$ improved both $\mathrm{CO}_{2}$ permeability and $\mathrm{CO}_{2} / \mathrm{CH}_{4}$ selectivity by $27 \%$ and $13 \%$, respectively. The higher permeability increments in the UiO-66 MMM are attributed to the easiness of $\mathrm{CO}_{2}$ to diffuse into its framework, compared to the higher steric hindrance in functionalized-MOFs, as discussed when showing BET adsorption data. The significant improvement is also contributed by its higher FFV increment in the MMM (see Table 1) and higher agglomeration degree of the UiO-66. The discussion follows accordingly in this section. Further Zr-MOF additions exhibited permeability-selectivity trade-off phenomenon more clearly where the selectivity reduced by $56 \%$ with $21 \mathrm{wt} \%$ UiO-66, $31 \%$ with $22 \mathrm{wt} \%$ UiO-66- $\mathrm{NH}_{2}$ and $27 \%$ with 24 wt\% UiO-66- $\mathrm{NHCOCH}_{3}$.

At the stated optimum loadings, the Zr-MOF addition was able to achieve ideal MMM morphology, presented as case 0 by Hashemifard et al. [90], and overcame the permeability-selectivity trade-off [91]. The enhanced permeability can be ascribed to the $\mathrm{CO}_{2}$-philic characteristics of the Zr-MOFs [39], where a stronger energetic interaction between $\mathrm{CO}_{2}$ (higher quadrupole moment than $\mathrm{CH}_{4}$ ) and the nanoparticle surfaces to occur at zero coverage. Besides higher gas diffusion in the Zr-MOFs, the NPs addition improved the MMM gas diffusivity by creating a third selective interface region [92] and the additional free volume in the interfacial region $[79,80]$. The NPs agglomeration was more prominent at the highest loading as discussed, and the selectivity reduction ought to be caused by the formation of non-selective by-pass channels in the agglomerates [79] and possibly micro-voids in the interface region [90], although it cannot be evidenced by SEM.

Fig. S8 shows the gas permeabilities and the membrane FFV values, calculated from the solid densities measured at $20^{\circ} \mathrm{C}$ with pressurized $\mathrm{He}$ cycles between 2 and 20 bar and polymer van der Waals volume [53]. FFV for 6FDA-DAM with $14 \mathrm{wt} \%$ UiO-66 increased the highest by $40 \%$, contributing to almost $100 \%$ increments for both $\mathrm{CO}_{2}$ (from 997 to 1912 Barrer) and $\mathrm{CH}_{4}$ (from 34 to 62 Barrer) permeabilities. Both $16 \mathrm{wt} \%$ UiO$66-\mathrm{NH}_{2}$ and $16 \mathrm{wt} \%$ UiO-66-NH- $\mathrm{COCH}_{3}$ only increased their membrane FFVs by $16 \%$ and $23 \%$ and enhanced their $\mathrm{CO}_{2}$ permeabilities by $23 \%$ and $27 \%$, respectively. However, it is important to note that the $\mathrm{CH}_{4}$ permeabilities in these membranes only increased by $11 \%$ and $18 \%$, respectively. The additional FFV in the MMM was formed due to the polymer chain packing disruptions (in agreement with the above-discussed modelling showing that the polymer density in the UiO-66/6FDA-DAM interface region was only $20 \%$ of that corresponding to the bulk polymer), especially in the NPs-polymer soft-delaminated interfacial region (refer to SEM images in Fig. S5). In the functionalized UiO-66 MMMs, the FFV increments were lower, in agreement with the expected stronger intermolecular interaction with the polar functional groups of the two MOFs.

Fig. 8(d) shows the as-prepared 6FDA-DAM neat membrane $\left(P_{\mathrm{CO} 2}\right.$ $=997 \pm 48$ Barrer, $\alpha_{\mathrm{CO} 2 / \mathrm{CH} 4}=29 \pm 3$ ) benchmarked to the 2008 Robeson upper bound [29]; positioned above the trade-off line and performed better than recently reported 6FDA-DAM MMMs with other MOFs. This outstanding performance was further enhanced by the incorporation of MOFs. 6FDA-DAM MMMs showed the best performance with $14 \mathrm{wt} \%$ of UiO-66 $\left(\mathrm{P}_{\mathrm{CO} 2}=1912\right.$ Barrer, $\left.\alpha_{\mathrm{CO} 2 / \mathrm{CH} 4}=31\right), 16 \mathrm{wt} \%$ of UiO-66- $\mathrm{NH}_{2}\left(\mathrm{P}_{\mathrm{CO} 2}=1223\right.$ Barrer, $\left.\alpha_{\mathrm{CO} 2 / \mathrm{CH} 4}=30\right)$ and $16 \mathrm{wt} \%$ of UiO-66-NH- $-\mathrm{COCH}_{3}\left(\mathrm{P}_{\mathrm{CO} 2}=1263\right.$ Barrer, $\left.\alpha_{\mathrm{CO} 2 / \mathrm{CH} 4}=33\right)$. It is worth mentioning that this is the highest $\mathrm{CO}_{2} / \mathrm{CH}_{4}$ separation selectivity value (33) achieved in this work, consistent with a positive influence of MOF functionalization on the textural and adsorption properties of the filler. For this highly permeable polymers any increase in selectivity is relevant. In any event, further addition of MOFs up to $21-24 \mathrm{wt} \%$ particle loading decreased the $\mathrm{CO}_{2} / \mathrm{CH}_{4}$ selectivity, and a permeabilityselectivity trade-off phenomenon took place, where the $\mathrm{CO}_{2} / \mathrm{CH}_{4}$ selectivities were lower than that of the neat membrane due to the intensive creation of defective transport paths. Overall, it is important to note that the use of UiO-66 and its functionalized derivatives are both beneficial to improve the separation shortcomings of a certain polymer depending on the improvement goals. For example, to improve the $\mathrm{CO}_{2}$ permeability of the low permeable Matrimid ${ }^{\circledR}$ using UiO-66 and to enhance the $\mathrm{CO}_{2} / \mathrm{CH}_{4}$ selectivity of the low selectivity PIMs using the functionalized UiO-66, as suggested in our separation performances..

Langmuir-Freundlich coefficients for the Zr-MOFs and the calculated permeabilities from an extended Maxwell model are presented in Table S5 and Table S6, in comparison with their experimental data. The calculation detail is also included in the Supporting Information. Please note that the calculation was only conducted up to the optimum loading (14-16 wt\%) in all the MMM systems, assuming these membranes possess ideal MMM morphologies. For UiO-66 MMM, the model underestimated both $\mathrm{CO}_{2}$ and $\mathrm{CH}_{4}$ permeabilities with relative errors of $15-30 \%$ and $13-26 \%$, respectively (see Fig. S9(a)). In the case of UiO66- $\mathrm{NH}_{2}$ and UiO-66-NH-COCH 3 MMMs, the predicted $\mathrm{CO}_{2}$ and $\mathrm{CH}_{4}$ permeabilities are in good agreement, with only a slight overestimation of less than $12 \%$ relative error (Fig. S9(b) and S9(c)). However, the model underestimated the $\mathrm{CH}_{4}$ permeability of UiO-66-NH- $\mathrm{COCH}_{3}$ MMM at $16 \mathrm{wt} \%$ loading by $20 \%$. Overall, the relative error increased with the increasing loading. A similar trend was also revealed in several other MMM systems [96-98]. This behavior can be explained by a few factors, such as: (i) the model does not consider the competitive sorption of $\mathrm{CO}_{2}$ and $\mathrm{CH}_{4}$; (ii) the model assumes an ideal morphology between both phases with homogeneous dispersion, while different degrees of agglomeration may be present in the Zr-MOFs (as shown in Section 3.2); and (iii) the model assumes the particles are spherical, while our Zr-MOFs have an octahedral form. 


\subsubsection{Performance at various $\mathrm{CO}_{2}$ partial pressures}

One of the advantages of membrane technology in natural gas processing is its high adaptability to various gas volumes and $\mathrm{CO}_{2}$ concentrations. To demonstrate the efficiency of the prepared MMMs in gas separation, we subjected each of the best-performing MMMs for binary gas separation with different $\mathrm{CO}_{2}$ content $(10-50 \%)$ in the feed gas at 2 bar pressure difference and $35^{\circ} \mathrm{C}$.

Fig. S10 shows the effect of $\mathrm{CO}_{2}$ partial pressure on the MMMs separation properties, where $\mathrm{CO}_{2}$ permeability increased with the increasing $\mathrm{CO}_{2}$ partial pressure in the feed gas. Conversely, it decreased the $\mathrm{CH}_{4}$ permeability and directly translated into an improvement in the $\mathrm{CO}_{2} / \mathrm{CH}_{4}$ selectivity. The addition of $\mathrm{Zr}$-MOFs to 6FDA-DAM polymer matrix assuredly increased its FFV and affected the gas diffusivity as well as gas solubility, thus the competitive sorption effects $[99,100]$. Interestingly the $\mathrm{CO}_{2}$ permeability in the UiO-66 MMMs increased more than in the functionalized UiO-66 MMMs. This suggests that competitive sorption is more prominent in these latter membranes and it may be influenced by their different filler-polymer interactions, and not by $\mathrm{CO}_{2}$-philicity that would favor MMMs containing functionalized UiO-66, in agreement with the already commented $\mathrm{CO}_{2}$ adsorption capacities in Table S2. The differences may also be influenced by the $\mathrm{Zr}$-MOF pore opening properties towards $\mathrm{CO}_{2}$ adsorption in the presence of the bulkier organic linkers with higher space steric hindrance and polarity, promoting selective $\mathrm{CO}_{2}$ transport over that of $\mathrm{CH}_{4}$. Fig. 9(a) shows their performances with regards to the 2008 Robeson upper bound for ease of comparison [29].

\subsubsection{Pure $\mathrm{CO}_{2}$ and mixed gas high-pressure separation performance}

$\mathrm{High} \mathrm{CO}_{2}$-partial presence can plasticize a glassy polymer $[76,101]$, and leads to an increase of the lower permeable component thus reducing the gas separation performance. We investigated the phenomenon by feeding pure $\mathrm{CO}_{2}$, and $\mathrm{CO}_{2} / \mathrm{CH}_{4}$ binary mixture (10:90 vol\% and 50:50 vol $\%$, see Fig. S11), up to 40 bar at $35^{\circ} \mathrm{C}$ and the permeability and selectivity were measured. Fig. 9(b) and Fig. S12 show the $\mathrm{CO}_{2}$ permeability as a function of $\mathrm{CO}_{2}$ pressure and its $\mathrm{CO}_{2}$ fluxes against the pressure difference. We observed a continuous decrease in permeability with increasing pressure, following the predicted behavior of the dual-mode sorption model $[102,103]$. Accordingly to our stabilization and measurement practice, no $\mathrm{CO}_{2}$-induced plasticization effect was observed for the neat 6FDA-DAM up to $40 \mathrm{bar}$, conflicting with the reported plasticization pressure for the same polymer in the 10-20 bar range [74,104]. The difference here could be attributed to their different polymer physical properties, i.e., molecular weight, density, and free volume, as previously discussed. A similar observation was reported in a MIL-53(Al) Matrimid 5218 MMM during a high-pressure single gas measurement [92]. Both functionalized MMMs showed a continuous decrease in $\mathrm{CO}_{2}$ permeability (decreasing gas solubility) from 5 to $40 \mathrm{bar}$, demonstrating the competitive sorption effects and the gradual saturation of the permeating gas in the membrane with increasing pressure. For 10:90 vol\% and 50:50 vol $\% \mathrm{CO}_{2}: \mathrm{CH}_{4}$ gas mixture separations, we witnessed no upward inflection in $\mathrm{CO}_{2}$ permeability in all membranes when measured between 5 and 40 bar at $35^{\circ} \mathrm{C}$ (Fig. S13 and S14) and only gradual $\mathrm{CO}_{2} / \mathrm{CH}_{4}$ selectivity reduction (Fig. 10(a-b)). However, there is a slight increase in $\mathrm{CH}_{4}$ permeability when tested with the $50 \mathrm{vol} \%$ of $\mathrm{CO}_{2}$ in feed content for the neat membrane, UiO-66, and UiO-66- $\mathrm{NH}_{2}$ MMMs.

The change in gas permeability with increasing feed pressure is influenced by either dual-mode adsorption transport or plasticization and the trend, in the case of binary feed mixture, can be observed by comparing $\mathrm{CO}_{2}$ and $\mathrm{CH}_{4}$ permeabilities at the lowest (5 bar) and the highest feed pressure (40 bar) $[67,105]$. For our membranes, $\mathrm{CO}_{2}$ permeability decreases with increasing pressure when tested with pure $\mathrm{CO}_{2}$ and $\mathrm{CO}_{2}: \mathrm{CH}_{4}$ binary mixture, which indicated the dominance of dual-mode adsorption $[105,106]$. The net reduction effects are significant as can be observed in Fig. 11. The continuous reduction of $\mathrm{CO}_{2}$ permeability in all measurements indicated the absence of $\mathrm{CO}_{2}$-induced plasticization in the thick membrane [106]. Despite the flux increments (as presented in Figs. S13 and S14), permeability reduction also indicated decreasing diffusion and permeation coefficient in the membrane matrices as a function of pressure. This is a good indication that the membrane showed no $\mathrm{CO}_{2}$-induced plasticization in the tested pressure range. Despite the known fact that the permeating gasses are adsorbed higher into the polymer matrix at elevated pressure, causing the increase in chain mobility and plasticization, we observed no such behavior [100,107,108]. Interestingly, Bachman et al. [104] also reported 6FDA-DAM with $25 \mathrm{wt} \% \mathrm{Ni}_{2}$ (dobdc), when tested with an equimolar of $\mathrm{CO}_{2}: \mathrm{CH}_{4}$ gas mixture, plasticization at $47 \mathrm{bar}$, despite the polymer $\mathrm{CO}_{2}$-induced plasticization pressure at $10 \mathrm{bar}$ in $\mathrm{CO}_{2}$ pure gas.

The increase of $\mathrm{CH}_{4}$ permeability in the neat polymer, UiO-66, and UiO-66- $\mathrm{NH}_{2}$ MMMs, as shown in Fig. 11(e) when tested with an equimolar $\mathrm{CO}_{2}: \mathrm{CH}_{4}$ binary mixture, was also observable in Fig. S14. Such behavior was explained by Bachman and Long [105] due to a lower Langmuir solubility component, as compared to Henry's Law component. Thus, the observation was concluded to be plasticization, most likely to be contributed by its higher competitive sorption effect in an equimolar feed mixture. Higher functionalization of UiO-66 seems to reduce the plasticization effect (almost zero net permeability reduction effect) and its permeability is dominated by dual-mode transport over the entire pressure range. Additionally, both neat 6FDA-DAM and UiO66 MMMs displayed a slight increase of $\mathrm{CO}_{2}$ permeability at $\sim$ 10-12 bar (Fig. 9(b) and S12). These inflections, however, do not
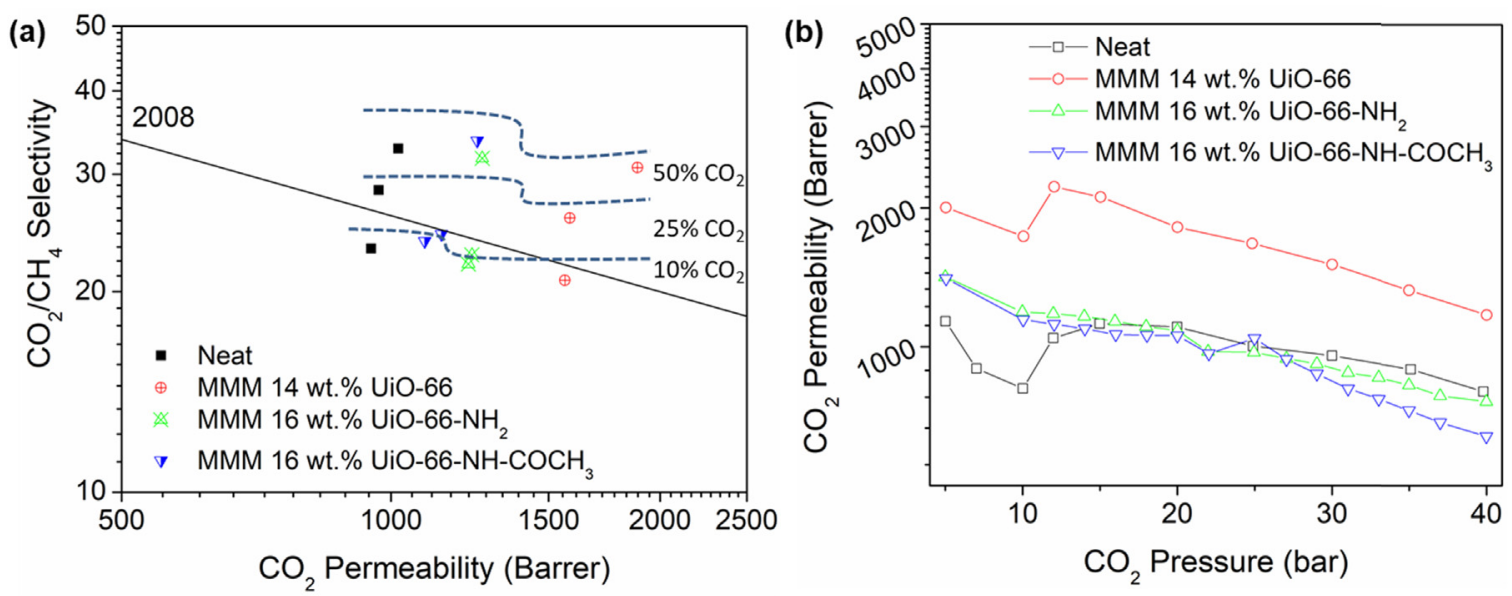

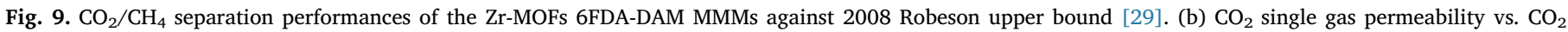
pressure, for the neat 6FDA-DAM and its best performing Zr-MOFs MMMs, measured at 5-40 bar. All measurements were conducted at $35{ }^{\circ} \mathrm{C}$. 

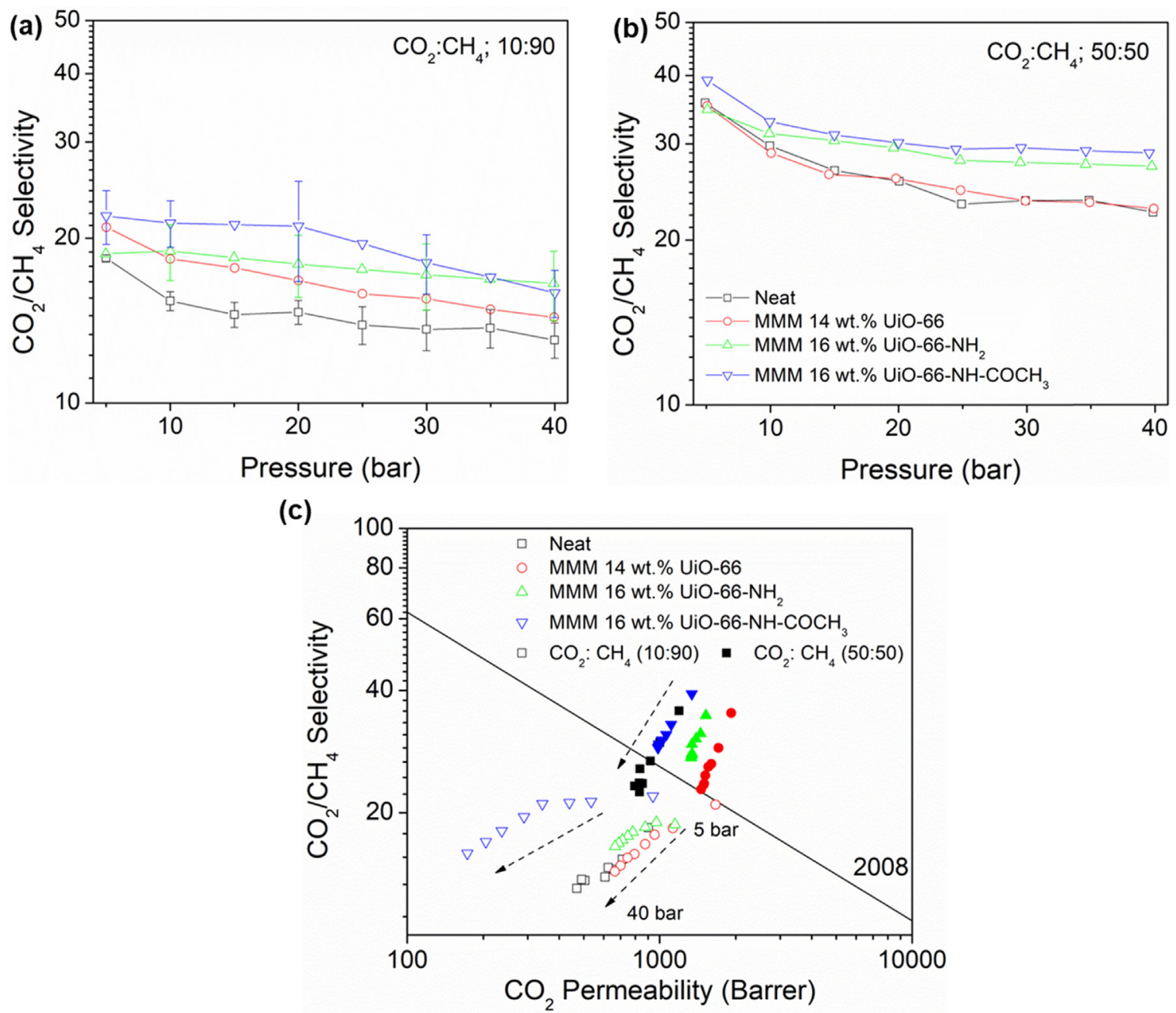

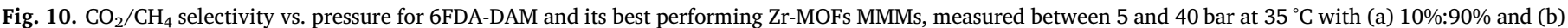
50\%:50\% $\mathrm{CO}_{2} / \mathrm{CH}_{4}$ gas mixtures. In (c), the data are represented against 2008 Robeson upper bound.

correspond to the plasticization points as the $\mathrm{CO}_{2}$ permeability further decreases with higher pressure. Thus there was no $\mathrm{CO}_{2}$-induced plasticization at the reported pressures.

Additionally, we can observe that the $\mathrm{CH}_{4}$ permeability decreased more than that of $\mathrm{CO}_{2}$, indicating that $\mathrm{CH}_{4}$ adsorption into the polymer matrix was suppressed at the high pressure. This may be explained by competitive sorption [99]: $\mathrm{CO}_{2}$ would penetrate faster into the membrane adsorption sites which associated with the nonequilibrium free volume in glass polymer and hindered the $\mathrm{CH}_{4}$ transport through the membrane. Furthermore, the extent of $\mathrm{CO}_{2}$-induced plasticization depends on a few factors including the membrane thickness [109], whose influence on our membranes (thickness range of 100-150 $\mu \mathrm{m}$ ) was not investigated. Fig. 10(c) shows the performances with regards to the 2008 Robeson upper bound [29] and shows that $\mathrm{CO}_{2}$ permeability and $\mathrm{CO}_{2} / \mathrm{CH}_{4}$ selectivity were both higher when tested with greater $\mathrm{CO}_{2}$ content in the feed mixture. This is related to the higher $\mathrm{CO}_{2}$ partial pressure and competitive adsorption, as previously discussed.

\section{Conclusions}

The syntheses of crystalline, high thermal stability Zr-based MOF nanoparticles, namely UiO-66 and UiO-66- $\mathrm{NH}_{2}$ in a uniform size of less than $50 \mathrm{~nm}$, were carried out. A post-synthetic modification of UiO-66- $\mathrm{NH}_{2}$ was successfully conducted to produce acetamide-functionalized UiO-66. 6FDADAM-based MMMs with the three Zr-MOFs at different loadings (5-24 wt \%) were fabricated and investigated for $\mathrm{CO}_{2}: \mathrm{CH}_{4}$ mixture separation. A significant $\mathrm{CO}_{2}$ permeability improvement of 6FDA-DAM to almost $100 \%$ was achieved with $14 \mathrm{wt} \%$ UiO- 66 MMMs while maintaining the selectivity when tested with an equimolar $\mathrm{CO}_{2}: \mathrm{CH}_{4}$ binary mixture at 2 bar pressure difference and $35^{\circ} \mathrm{C}$. MMMs with $16 \mathrm{wt} \%$ of both UiO-66- $\mathrm{NH}_{2}$ and UiO-66$\mathrm{NH}-\mathrm{COCH}_{3}$ improved the $\mathrm{CO}_{2}$ permeability by $23 \%$ and $27 \%$, respectively, with a small but significant improvement in selectivity for the UiO-66-NH$\mathrm{COCH}_{3} \mathrm{MMMs}$ by $13 \%$, at similar measurement conditions. High-pressure $\mathrm{CO}_{2}$ single gas and $\mathrm{CO}_{2}: \mathrm{CH}_{4}\left(10-90 \% \mathrm{CO}_{2}\right)$ binary mixed gas measurements at $35^{\circ} \mathrm{C}$ showed highly promising results, where $\mathrm{CO}_{2}$-induced plasticization was not observed up to $40 \mathrm{bar}$, for all the membranes. The enhanced membrane performance was mirrored by its improved physical properties; i.e., free fractional volumes and glass transition temperatures. The atomistic modelling of the UiO-66/6FDA-DAM interface was consistent with a moderate MOF surface coverage by the polymer with an absence of a polymer penetration in the MOF porosity, which had no negative impact on the membrane performances. Therefore, the developed membranes have demonstrated their potential for natural gas purification process and are substantially beneficial for industrial scale gas separation.

\section{Acknowledgments}

The authors acknowledge the financial support of EACEA/European Commission, within the "Erasmus Mundus Doctorate in Membrane Engineering - EUDIME" (ERASMUS MUNDUS Programme 2009-2013, FPA n. 2011-0014, SGA n. 2012-1719), Operational Programme Prague - Competitiveness (CZ.2.16/3.1.00/24501), "National Program of 

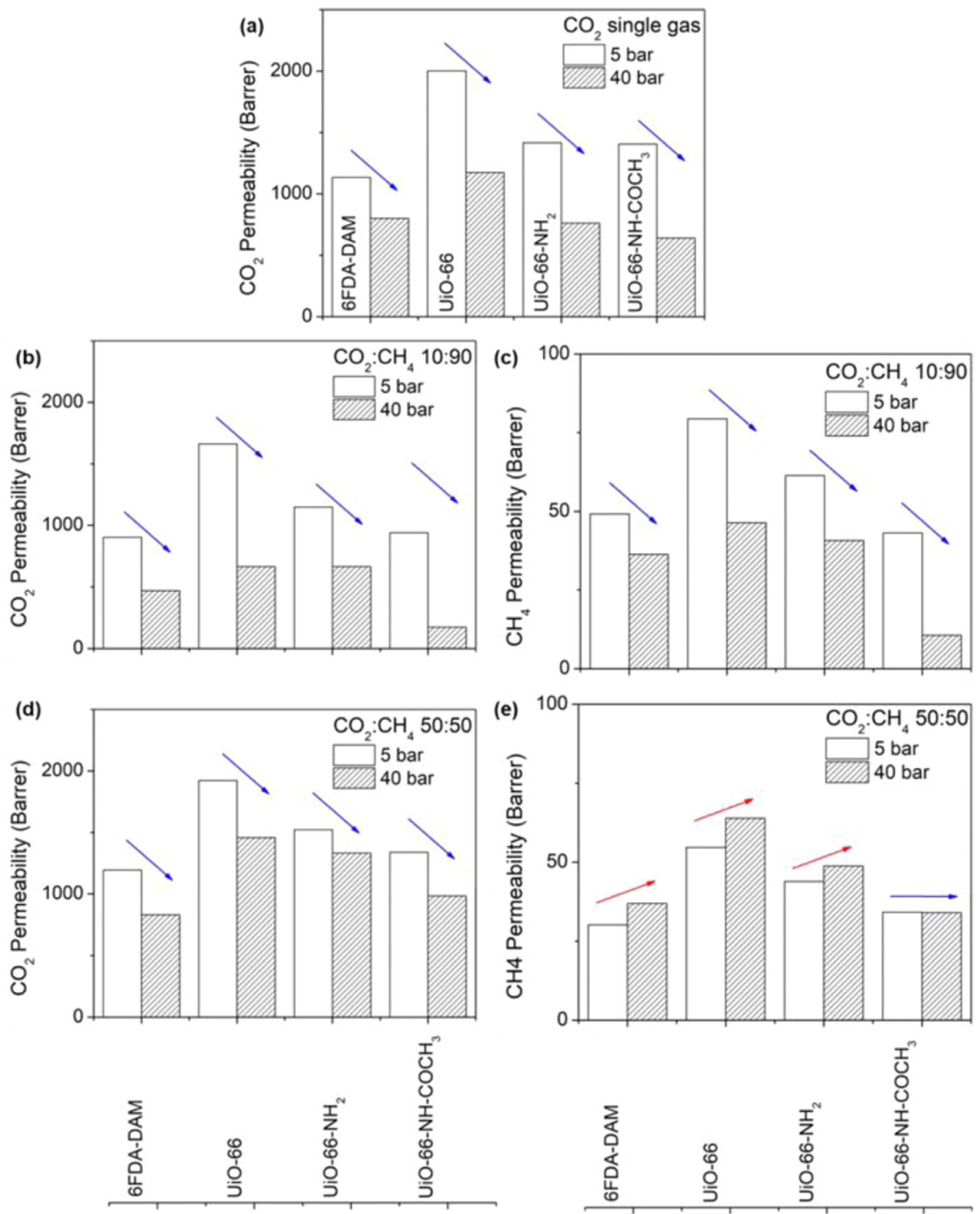

Fig. 11. Gas permeability values for 6FDA-DAM and its respective Zr-MOF MMMs when measured at 5 and 40 bar, at $35^{\circ} \mathrm{C}$ with (a) pure $\mathrm{CO}_{2}$ single gas, (b \& c) $10: 90$ $\mathrm{CO}_{2}: \mathrm{CH}_{4}$ binary mixture, and (d \& e) $50: 50 \mathrm{CO}_{2}: \mathrm{CH}_{4}$ binary mixture.

Sustainability" of Czech Republic, (NPU I LO1613) MSMT-43760/2015 and MAT2016-77290-R from the Spanish MINECO and FEDER, the Aragón Government (DGA, T05) and the European Social Fund. The microscopy work was carried out in the Laboratorio de Microscopías Avanzadas at the Instituto de Nanociencia de Aragón (LMA-INA, Universidad de Zaragoza). The authors would like to acknowledge the use of the Servicio General de Apoyo a la Investigación-SAI (Universidad de Zaragoza). G.M. thanks Institut Universitaire de France for its support.

\section{Appendix A. Supplementary material}

Supplementary data associated with this article can be found in the online version at http://dx.doi.org/10.1016/j.memsci.2018.04.040.

\section{References}

[1] G. George, N. Bhoria, S. Alhallaq, A. Abdala, V. Mittal, Polymer membranes for acid gas removal from natural gas, Sep. Purif. Technol. 158 (2016) 333-356.

[2] E. Adatoz, A.K. Avci, S. Keskin, Opportunities and challenges of MOF-based membranes in gas separations, Sep. Purif. Technol. 152 (2015) 207-237. 
[3] Y. Alcheikhhamdon, M. Hoorfar, Natural gas purification from acid gases using membranes: a review of the history, features, techno-commercial challenges, and process intensification of commercial membranes, Chem. Eng. Process. Process. Intensif. 120 (2017).

[4] R.W. Baker, Future directions of membrane gas separation technology, Ind. Eng. Chem. Res. 41 (2002) 1393-1411.

[5] M. Vinoba, M. Bhagiyalakshmi, Y. Alqaheem, A.A. Alomair, A. Pérez, M.S. Rana, Recent progress of fillers in mixed matrix membranes for $\mathrm{CO}_{2}$ separation: a review, Sep. Purif. Technol. 188 (2017) 431-450.

[6] M. Farnam, H. Mukhtar, A. Shariff, Analysis of the influence of CMS variable percentages on pure PES membrane gas separation performance, Procedia Eng. 148 (2016) 1206-1212.

[7] M.Y. Wey, H.H. Tseng, C. Kai Chiang, Effect of MFI zeolite intermediate layers on gas separation performance of carbon molecular sieve (CMS) membranes, J. Memb. Sci. 446 (2013) 220-229.

[8] N. Jusoh, Y.F. Yeong, K.K. Lau, A.M. Shariff, Enhanced gas separation performance using mixed matrix membranes containing zeolite $\mathrm{T}$ and 6FDA-durene polyimide, J. Memb. Sci. 525 (2017) 175-186.

[9] H. Zhao, Q. Xie, X. Ding, J. Chen, M. Hua, X. Tan, Y. Zhang, High performance post-modified polymers of intrinsic microporosity (PIM-1) membranes based on multivalent metal ions for gas separation, J. Memb. Sci. 514 (2016) 305-312.

[10] D. Zhao, J. Ren, Y. Wang, Y. Qiu, H. Li, K. Hua, X. Li, J. Ji, M. Deng, High $\mathrm{CO}_{2}$ separation performance of Pebax ${ }^{\otimes}$ CNTs/GTA mixed matrix membranes, J. Memb. Sci. 521 (2017) 104-113.

[11] Q. Huang, J. Ding, X. Huang, X. Wei, W. Wang, Experimental and computational investigation of $\mathrm{CO}_{2}$ capture on mix-ligand metal-organic framework UiO-66, Energy Procedia 105 (2017) 4395-4401.

[12] A. Perea-Cachero, J. Sánchez-Laínez, Á. Berenguer-Murcia, D. Cazorla-Amorós, C. Téllez, J. Coronas, A new zeolitic hydroxymethylimidazolate material and its use in mixed matrix membranes based on 6FDA-DAM for gas separation, J. Memb. Sci. 544 (2017) 88-97.

[13] M. Zamidi Ahmad, M. Navarro, M. Lhotka, B. Zornoza, C. Téllez, V. Fila, J. Coronas, Enhancement of $\mathrm{CO}_{2} / \mathrm{CH}_{4}$ separation performances of 6FDA-based copolyimides mixed matrix membranes embedded with UiO-66 nanoparticles, Sep. Purif. Technol. 192 (2018) 465-474.

[14] P.D. Sutrisna, J. Hou, H. Li, Y. Zhang, V. Chen, Improved operational stability of Pebax-based gas separation membranes with ZIF-8: a comparative study of flat sheet and composite hollow fibre membranes, J. Memb. Sci. 524 (2017) 266-279.

[15] L.J. van Rooyen, H. Bissett, M.C. Khoathane, J. Karger-Kocsis, Gas barrier properties of oxyfluorinated graphene filled polytetrafluoroethylene nanocomposites, Carbon 109 (2016) 30-39.

[16] H. Ha, J. Park, S. Ando, C. Bin Kim, K. Nagai, B.D. Freeman, C.J. Ellison, Gas permeation and selectivity of poly(dimethylsiloxane)/graphene oxide composite elastomer membranes, J. Memb. Sci. 518 (2016) 131-140.

[17] O.M. Yaghi, M. O'Keeffe, N.W. Ockwig, H.K. Chae, M. Eddaoudi, J. Kim, Reticular synthesis and the design of new materials, Nature 423 (2003) 705-714.

[18] G. Férey, Hybrid porous solids: past, present, future, Chem. Soc. Rev. 37 (2008) 191-214.

[19] G. Férey, Microporous solids: from organically templated inorganic skeletons to hybrid frameworks...Ecumenism in chemistry, Chem. Mater. 13 (2001) 3084-3098.

[20] G. Maurin, C. Serre, A. Cooper, G. Férey, The new age of MOFs and of their porousrelated solids, Chem. Soc. Rev. 46 (2017) 3104-3107.

[21] B.F. Hoskins, R. Robson, Infinite polymeric frameworks consisting of three dimensionally linked rod-like segments, J. Am. Chem. Soc. 111 (1989) 5962-5964.

[22] X. Yan, S. Komarneni, Z. Zhang, Z. Yan, Extremely enhanced $\mathrm{CO}_{2}$ uptake by HKUST-1 metal-organic framework via a simple chemical treatment, Microporous Mesoporous Mater. 183 (2014) 69-73.

[23] A.R. Millward, O.M. Yaghi, Metal-organic frameworks with exceptionally high capacity for storage of carbon dioxide at room temperature, J. Am. Chem. Soc. 127 (2005) 17998-17999.

[24] O.K. Farha, I. Eryazici, N.C. Jeong, B.G. Hauser, C.E. Wilmer, A.A. Sarjeant, R.Q. Snurr, S.T. Nguyen, A.Ö. Yazaydin, J.T. Hupp, Metal-organic framework materials with ultrahigh surface areas: is the sky the limit? J. Am. Chem. Soc. 134 (2012) 15016-15021.

[25] K. Adil, Y. Belmabkhout, R.S. Pillai, A. Cadiau, P.M. Bhatt, A.H. Assen, G. Maurin, M. Eddaoudi, Gas/vapour separation using ultra-microporous metal-organic frameworks: insights into the structure/separation relationship, Chem. Soc. Rev. 46 (2017) 3402-3430.

[26] G. Férey, C. Serre, Large breathing effects in three-dimensional porous hybrid matter: facts, analyses, rules and consequences, Chem. Soc. Rev. 38 (2009) $1380-1399$.

[27] G. Férey, C. Serre, T. Devic, G. Maurin, H. Jobic, P.L. Llewellyn, G. De Weireld, A. Vimont, M. Daturi, J.-S. Chang, Why hybrid porous solids capture greenhouse gases? Chem. Soc. Rev. 40 (2011) 550-562.

[28] A. Schneemann, V. Bon, I. Schwedler, I. Senkovska, S. Kaskel, R.A. Fischer, Flexible metal-organic frameworks, Chem. Soc. Rev. 43 (2014) 6062-6096.

[29] L.M. Robeson, The upper bound revisited, J. Memb. Sci. 320 (2008) 390-400.

[30] T. Bae, J.S. Lee, W. Qiu, W.J. Koros, C.W. Jones, MOF membranes A high-performance gas-separation membrane containing submicrometer-sized metal - organic framework crystals, Angew. Chem., Int. Ed. (2010) 9863-9866.

[31] A.F. Bushell, M.P. Attfield, C.R. Mason, P.M. Budd, Y. Yampolskii, L. Starannikova, A. Rebrov, F. Bazzarelli, P. Bernardo, J. Carolus Jansen, M. Lanč, K. Friess, V. Shantarovich, V. Gustov, V. Isaeva, Gas permeation parameters of mixed matrix membranes based on the polymer of intrinsic microporosity PIM-1 and the zeolitic imidazolate framework ZIF-8, J. Memb. Sci. 427 (2013) 48-62.
[32] T. Li, Y. Pan, K.-V. Peinemann, Z. Lai, Carbon dioxide selective mixed matrix composite membrane containing ZIF-7 nano-fillers, J. Memb. Sci. 425-426 (2013) $235-242$.

[33] V. Nafisi, M.B. Hägg, Development of dual layer of ZIF-8/PEBAX-2533 mixed matrix membrane for $\mathrm{CO}_{2}$ capture, J. Memb. Sci. 459 (2014) 244-255.

[34] L. Cao, F. Lv, Y. Liu, W. Wang, Y. Huo, X. Fu, R. Sun, Z. Lu, A high performance $\mathrm{O}_{2}$ selective membrane based on CAU-1- $\mathrm{NH}_{2} @$ polydopamine and the PMMA polymer for Li-air batteries, Chem. Commun. (Camb.). 51 (2015) 1-4.

[35] G.M. Shi, T. Yang, T.S. Chung, Polybenzimidazole (PBI)/zeolitic imidazolate frameworks (ZIF-8) mixed matrix membranes for pervaporation dehydration of alcohols, J. Memb. Sci. 415-416 (2012) 577-586.

[36] S. Øien, D. Wragg, H. Reinsch, S. Svelle, S. Bordiga, C. Lamberti, K.P. Lillerud, Detailed structure analysis of atomic positions and defects in zirconium metalorganic frameworks, Cryst. Growth Des. 14 (2014) 5370-5372.

[37] L. Valenzano, B. Civalleri, S. Chavan, S. Bordiga, M.H. Nilsen, S. Jakobsen, K.P. Lillerud, C. Lamberti, Disclosing the complex structure of UiO-66 metal organic framework: a synergic combination of experiment and theory, Chem. Mater. 23 (2011) 1700-1718.

[38] Q. Yang, A.D. Wiersum, H. Jobic, V. Guillerm, C. Serre, P.L. Llewellyn, G. Maurin, Understanding the thermodynamic and kinetic behavior of the $\mathrm{CO}_{2} / \mathrm{CH}_{4}$ gas mixture within the porous zirconium terephthalate UiO-66(Zr): a joint experimental and modeling approach, J. Phys. Chem. C. 115 (2011) 13768-13774.

[39] S. Biswas, P. Van Der Voort, A general strategy for the synthesis of functionalised UiO-66 frameworks: characterisation, stability and $\mathrm{CO}_{2}$ adsorption properties, Eur. J. Inorg. Chem. (2013) 2154-2160.

[40] J.H. Cavka, S. Jakobsen, U. Olsbye, N. Guillou, C. Lamberti, S. Bordiga, K.P. Lillerud, A. New, Zirconium inorganic building brick forming metal organic frameworks with exceptional stability, J. Am. Chem. Soc. 6 (2008) 13850-13851.

[41] Y.M. Xu, T.S. Chung, High-performance UiO-66/polyimide mixed matrix membranes for ethanol, isopropanol and n-butanol dehydration via pervaporation, J. Memb. Sci. 531 (2017) 16-26.

[42] G.E. Cmarik, M. Kim, S.M. Cohen, K.S. Walton, Tuning the adsorption properties of UiO-66 via ligand functionalization, Langmuir 28 (2012) 15606-15613.

[43] D.H. Hong, M.P. Suh, Enhancing $\mathrm{CO}_{2}$ separation ability of a metal-organic framework by post-synthetic ligand exchange with flexible aliphatic carboxylates, Chem. Eur. J. 20 (2014) 426-434.

[44] Y. Cao, Y. Zhao, Z. Lv, F. Song, Q. Zhong, Preparation and enhanced $\mathrm{CO}_{2}$ ad sorption capacity of UiO-66/graphene oxide composites, J. Ind. Eng. Chem. 27 (2015) 102-107.

[45] T. Ahnfeldt, D. Gunzelmann, J. Wack, J. Senker, N. Stock, Controlled modification of the inorganic and organic bricks in an Al-based MOF by direct and post-synthetic synthesis routes, CrystEngComm 14 (2012) 4126-4136.

[46] K.K. Tanabe, S.M. Cohen, Postsynthetic modification of metal-organic frameworks - a progress report, Chem. Soc. Rev. 40 (2011) 498-519.

[47] N. Tien-Binh, H. Vinh-Thang, X.Y. Chen, D. Rodrigue, S. Kaliaguine, Polymer functionalization to enhance interface quality of mixed matrix membranes for high $\mathrm{CO}_{2} / \mathrm{CH}_{4}$ gas separation, J. Mater. Chem. A. 3 (2015) 15202-15213.

[48] M.W. Anjum, F. Vermoortele, A.L. Khan, B. Bueken, D.E. De Vos, I.F.J. Vankelecom, Modulated UiO-66-based mixed-matrix membranes for $\mathrm{CO}_{2}$ separation, ACS Appl. Mater. Interfaces 7 (2015) 25193-25201.

[49] Q. Xin, T. Liu, Z. Li, S. Wang, Y. Li, Z. Li, J. Ouyang, Z. Jiang, H. Wu, Mixed matrix membranes composed of sulfonated poly(ether ether ketone) and a sulfonated metal-organic framework for gas separation, J. Memb. Sci. 488 (2015) 67-78.

[50] L. Hou, L. Wang, N. Zhang, Z. Xie, D. Dong, Polymer brushes on metal-organic frameworks by UV-induced photopolymerization, Polym. Chem. 7 (2016) $5828-5834$

[51] M. Kandiah, S. Usseglio, S. Svelle, U. Olsbye, K.P. Lillerud, M. Tilset, Post-synthetic modification of the metal-organic framework compound UiO-66, J. Mater. Chem. 20 (2010).

[52] S.J. Garibay, S.M. Cohen, Isoreticular synthesis and modification of frameworks with the UiO-66 topology, Chem. Commun. 46 (2010) 7700-7702.

[53] N.R. Horn, A critical review of free volume and occupied volume calculation methods, J. Memb. Sci. 518 (2016) 289-294.

[54] J. Park, D.R. Paul, Correlation and Prediction of gas permeability in glassy polymer membrane materials via a modified free volume based group contribution method, J. Memb. Sci. 125 (1997) 23-39.

[55] S. Shahid, K. Nijmeijer, High pressure gas separation performance of mixed-matrix polymer membranes containing mesoporous Fe(BTC), J. Memb. Sci. 459 (2014) 33-44.

[56] R. Semino, N.A. Ramsahye, A. Ghoufi, G. Maurin, Microscopic model of the metalorganic framework/polymer interface: a first step toward understanding the compatibility in mixed matrix membranes, ACS Appl. Mater. Interfaces 8 (2016) 809-819.

[57] R. Semino, J.C. Moreton, N.A. Ramsahye, S.M. Cohen, G. Maurin, Understanding the origins of metal-organic framework/polymer compatibility, Chem. Sci. 9 (2018) 315-324.

[58] J.M. Wang, R.M. Wolf, J.W. Caldwell, P. a Kollman, D. a Case, Development and testing of a general amber force field, J. Comput. Chem. 25 (2004) 1157-1174.

[59] B.L. Eggimann, A.J. Sunnarborg, H.D. Stern, A.P. Bliss, J.I. Siepmann, An online parameter and property database for the TraPPE force field, Mol. Simul. 40 (2014) $101-105$.

[60] J.P. Perdew, K. Burke, M. Ernzerhof, Generalized gradient approximation made simple, Phys. Rev. Lett. 77 (1996) 3865-3868.

[61] L.J. Abbott, K.E. Hart, C.M. Colina, Polymatic: a generalized simulated polymerization algorithm for amorphous polymers, Theor. Chem. Acc. 132 (2013) $1-19$. 
[62] H.J.C. Berendsen, J.P.M. Postma, W.F. van Gunsteren, A. DiNola, J.R. Haak, Molecular dynamics with coupling to an external bath, J. Chem. Phys. 81 (1984) 3684-3690.

[63] S. Plimpton, Fast parallel algorithms for short-range molecular dynamics, J. Comput. Phys. 117 (1995) 1-19.

[64] I.T. Todorov, W. Smith, K. Trachenko, M.T. Dove, DL POLY 3: new dimensions in molecular dynamics simulations via massive parallelism, J. Mater. Chem. 16 (2006) 1911-1918.

[65] Q. Yang, C. Zhong, Molecular simulation of carbon dioxide/methane/hydrogen mixture adsorption in metal-organic frameworks, J. Phys. Chem. B 110 (2006) 17776-17783.

[66] L.H. Wee, Y. Li, K. Zhang, P. Davit, S. Bordiga, J. Jiang, I.F.J. Vankelecom, J.A. Martens, Submicrometer-sized ZIF-71 filled organophilic membranes for improved bioethanol recovery: mechanistic insights by Monte Carlo simulation and FTIR spectroscopy, Adv. Funct. Mater. 25 (2015) 516-525.

[67] T.-H. Bae, J.R. Long, $\mathrm{CO}_{2} / \mathrm{N}_{2}$ separations with mixed-matrix membranes containing $\mathrm{Mg}_{2}$ (dobdc) nanocrystals, Energy Environ. Sci. 6 (2013) 3565-3569.

[68] M.J. Katz, Z.J. Brown, Y.J. Colón, P.W. Siu, K. a Scheidt, R.Q. Snurr, J.T. Hupp, O.K. Farha, A facile synthesis of UiO-66, UiO-67 and their derivatives, Chem. Commun. 49 (2013) 9449-9451.

[69] S. Castarlenas, C. Tellez, J. Coronas, Gas separation with mixed matrix membranes obtained from MOF UiO-66-graphite oxide hybrids, J. Membr. Sci. 526 (2017) $205-211$.

[70] J. Shen, G. Liu, K. Huang, Q. Li, K. Guan, Y. Li, W. Jin, UiO-66-polyether block amide mixed matrix membranes for $\mathrm{CO}_{2}$ separation, J. Memb. Sci. 513 (2016) $155-165$.

[71] O.G. Nik, X.Y. Chen, S. Kaliaguine, Functionalized metal organic frameworkpolyimide mixed matrix membranes for $\mathrm{CO}_{2} / \mathrm{CH}_{4}$ separation, J. Memb. Sci. 413-414 (2012) 48-61.

[72] M.R. Khdhayyer, E. Esposito, A. Fuoco, M. Monteleone, L. Giorno, J.C. Jansen, M.P. Attfield, P.M. Budd, Mixed matrix membranes based on UiO-66 MOFs in the polymer of intrinsic microporosity PIM-1, Sep. Purif. Technol. 173 (2017) 304-313.

[73] H. Wu, Y.S. Chua, V. Krungleviciute, M. Tyagi, P. Chen, T. Yildirim, W. Zhou, Unusual and highly tunable missing-linker defects in zirconium metal-organic framework UiO-66 and their important effects on gas adsorption, J. Am. Chem. Soc. 135 (2013) 10525-10532.

[74] B. Zornoza, C. Téllez, J. Coronas, O. Esekhile, W.J. Koros, Mixed matrix membranes based on 6FDA polyimide with silica and zeolite microsphere dispersed phases, AIChE J. 61 (2015) 4481-4490.

[75] M. Loloei, A. Moghadassi, M. Omidkhah, A. Ebadi Amooghin, Upscaling and its application in numerical simulation of long-term $\mathrm{CO}_{2}$ storage, Greenh. Gases Sci. Technol. 2 (2015) 530-544.

[76] J.H. Kim, W.J. Koros, D.R. Paul, Effects of $\mathrm{CO}_{2}$ exposure and physical aging on the gas permeability of thin 6FDA-based polyimide membranes. Part 1 . Without crosslinking, J. Memb. Sci. 282 (2006) 21-31.

[77] C.K. Yeom, J.M. Lee, Y.T. Hong, K.Y. Choi, S.C. Kim, Analysis of permeation transients of pure gases through dense polymeric membranes measured by a new permeation apparatus, J. Memb. Sci. 166 (2000) 71-83.

[78] L. Xu, C. Zhang, M. Rungta, W. Qiu, J. Liu, W.J. Koros, Formation of defect-free 6FDA-DAM asymmetric hollow fiber membranes for gas separations, J. Memb. Sci. 459 (2014) 223-232.

[79] B. Zornoza, C. Tellez, J. Coronas, J. Gascon, F. Kapteijn, Metal organic framework based mixed matrix membranes: an increasingly important field of research with a large application potential, Microporous Mesoporous Mater. 166 (2013) 67-78.

[80] H. Lin, M. Yavari, Upper bound of polymeric membranes for mixed-gas $\mathrm{CO}_{2} / \mathrm{CH}_{4}$ separations, J. Memb. Sci. 475 (2015) 101-109.

[81] R. Semino, J.P. Durholt, R. Schmid, G. Marin, Multiscale modeling of the HKUST1/polyvinyl alcohol interface: from an atomistic to a coarse graining approach, J. Phys. Chem. C 121 (2017) 21491-21496.

[82] D. Hofmann, M. Heuchel, Y. Yampolskii, V. Khotimskii, V. Shantarovich, Free volume distributions in ultrahigh and lower free volume polymers: comparison between molecular modeling and positron lifetime studies, Macromolecules 35 (2002) 2129-2140.

[83] S. Bhattacharya, K.E. Gubbins, Fast method for computing pore size distributions of model materials, Langmuir 22 (2006) 7726-7731.

[84] F. Cacho-Bailo, G. Caro, M. Etxeberria, O. Karvan, C. Tellez, J. Coronas, MOFpolymer enhanced compatibility: post-annealed zeolite imidazolate framework membranes inside polyimide hollow fibers, RSC Adv. (2016) 5881-5889.

[85] R.J. Swaidan, X. Ma, E. Litwiller, I. Pinnau, Enhanced propylene/propane separation by thermal annealing of an intrinsically microporous hydroxyl-functionalized polyimide membrane, J. Memb. Sci. 495 (2015) 235-241.

[86] J.T. Vaughn, W.J. Koros, J.R. Johnson, O. Karvan, Effect of thermal annealing on a novel polyamide-imide polymer membrane for aggressive acid gas separations, $\mathrm{J}$. Memb. Sci. 401-402 (2012) 163-174.

[87] C. Hibshman, C.J. Cornelius, E. Marand, The gas separation effects of annealing polyimide-organosilicate hybrid membranes, J. Memb. Sci. 211 (2003) 25-40.

[88] C. Zhang, P. Li, B. Cao, Decarboxylation crosslinking of polyimides with high $\mathrm{CO}_{2}$ $\mathrm{CH}_{4}$ separation performance and plasticization resistance, J. Memb. Sci. 528 (2017) 206-216.

[89] M. Askari, T.-S. Chung, Natural gas purification and olefin/paraffin separation using thermal cross-linkable co-polyimide/ZIF-8 mixed matrix membranes, J. Memb. Sci. 444 (2013) 173-183.

[90] S.A. Hashemifard, A.F. Ismail, T. Matsuura, Prediction of gas permeability in mixed matrix membranes using theoretical models, J. Memb. Sci. 347 (2010) 53-61.

[91] B.D. Freeman, Basis of permeability/selectivity tradeoff relations in polymeric gas separation membranes, Macromolecules 32 (1999) 375-380.

[92] S. Shahid, K. Nijmeijer, Performance and plasticization behavior of polymer-MOF membranes for gas separation at elevated pressures, J. Memb. Sci. 470 (2014) 166-177.

[93] M. Safak Boroglu, A.B. Yumru, Gas separation performance of 6FDA-DAM-ZIF-11 mixed-matrix membranes for $\mathrm{H}_{2} / \mathrm{CH}_{4}$ and $\mathrm{CO}_{2} / \mathrm{CH}_{4}$ separation, Sep. Purif. Technol. 173 (2017) 269-279.

[94] A. Sabetghadam, B. Seoane, D. Keskin, N. Duim, T. Rodenas, S. Shahid, S. Sorribas, C. Le Guillouzer, G. Clet, C. Tellez, M. Daturi, J. Coronas, F. Kapteijn, J. Gascon, Metal organic framework crystals in mixed-matrix membranes: impact of the filler morphology on the gas separation performance, Adv. Funct. Mater. (2016) 3154-3163.

[95] H. Mao, S. Zhang, Mixed-matrix membranes incorporated with porous shapepersistent organic cages for gas separation, J. Colloid Interface Sci. 490 (2017) 29-36.

[96] B. Seoane, J.M. Zamaro, C. Téllez, J. Coronas, Insight into the crystal synthesis, activation and application of ZIF-20, RSC Adv. 1 (2011) 917-922.

[97] V. Martin-Gil, A. Lopez, P. Hrabanek, R. Mallada, I.F.J. Vankelecom, V. Fila, Study of different titanosilicate (TS-1 and ETS-10) as fillers for mixed matrix membranes for $\mathrm{CO}_{2} / \mathrm{CH}_{4}$ gas separation applications, J. Memb. Sci. 523 (2017) 24-35.

[98] M. Etxeberria-Benavides, O. David, T. Johnson, M.M. Łozińska, A. Orsi, P.A. Wright, S. Mastel, R. Hillenbrand, F. Kapteijn, J. Gascon, High performance mixed matrix membranes (MMMs) composed of ZIF-94 filler and 6FDA-DAM polymer, J. Memb. Sci. 550 (2018) 198-207.

[99] W.J. Koros, R.T. Chern, V. Stannett, H.B. Hopfenberg, A model for permeation of mixed gases and vapors in glassy polymers, J. Polym. Sci. B. 19 (1981) 1513-1530.

[100] T. Visser, N. Masetto, M. Wessling, Materials dependence of mixed gas plastici zation behavior in asymmetric membranes, J. Memb. Sci. 306 (2007) 16-28.

[101] L. Cui, W. Qiu, D.R. Paul, W.J. Koros, Responses of 6FDA-based polyimide thin membranes to $\mathrm{CO}_{2}$ exposure and physical aging as monitored by gas permeability, Polymer 52 (2011) 5528-5537.

[102] V. Stannett, The transport of gases in synthetic polymeric membranes - an historic perspective, J. Memb. Sci. 3 (1978) 97-115.

[103] M. Saberi, A.A. Dadkhah, S.A. Hashemifard, Modeling of simultaneous competitive mixed gas permeation and $\mathrm{CO}_{2}$ induced plasticization in glassy polymers, $\mathrm{J}$. Memb. Sci. 499 (2016) 164-171.

[104] J.E. Bachman, Z.P. Smith, T. Li, T. Xu, J.R. Long, Enhanced ethylene separation and plasticization resistance in polymer membranes incorporating metal-organic framework nanocrystals, Nat. Mater. 15 (2016) 845-849.

[105] J.E. Bachman, J.R. Long, Plasticization-resistant $\mathrm{Ni}_{2}$ (dobdc)/polyimide composite membranes for the removal of $\mathrm{CO}_{2}$ from natural gas, Energy Environ. Sci. 9 (2016) 2031-2036.

[106] T. Visser, G.H. Koops, M. Wessling, On the subtle balance between competitive sorption and plasticization effects in asymmetric hollow fiber gas separation membranes, J. Memb. Sci. 252 (2005) 265-277.

[107] S. Kanehashi, T. Nakagawa, K. Nagai, X. Duthie, S. Kentish, G. Stevens, Effects of carbon dioxide-induced plasticization on the gas transport properties of glassy polyimide membranes, J. Memb. Sci. 298 (2007) 147-155.

[108] A. Bos, I.G.M. Pünt, M. Wessling, H. Strathmann, $\mathrm{CO}_{2}$-induced plasticization phenomena in glassy polymers, J. Memb. Sci. 155 (1999) 67-78.

[109] M. Wessling, M. Lidon Lopez, H. Strathmann, Accelerated plasticization of thinfilm composite membranes used in gas separation, Sep. Purif. Technol. 24 (2001) 223-233. 